\title{
Richer color experience in observers with multiple photopigment opsin genes
}

\author{
KIMBERLY A. JAMESON and SUSAN M. HIGHNOTE \\ University of California at San Diego, La Jolla, California \\ and \\ LINDA M. WASSERMAN \\ University of California at San Diego School of Medicine, La Jolla, California
}

\begin{abstract}
Traditional color vision theory posits that three types of retinal photopigments transduce light into a trivariate neural color code, thereby explaining color-matching behaviors. This principle of trichromacy is in need of reexamination in view of molecular genetics results suggesting that a substantial percentage of women possess more than three classes of retinal photopigments. At issue is the question of whether four-photopigment retinas necessarily yield trichromatic color perception. In the present paper, we review results and theory underlying the accepted photoreceptor-based model of trichromacy. A review of the psychological literature shows that gender-linked differencesin color perception warrant further investigation of retinal photopigment classes and color perception relations. We use genetic analyses to examine an important position in the gene sequence, and we empirically assess and compare the color perception of individuals possessing more than three retinal photopigment genes with those possessing fewer retinal photopigment genes. Women with four-photopigment genotypes are found to perceive significantly more chromatic appearances in comparison with either male or female trichromat controls. We provide a rationale for this previously undetected finding and discuss implications for theories of color perception and gender differences in color behavior.
\end{abstract}

The recent growth of molecular genetics research has generated much interest in the relations between genetic potentialities and human behaviors. Although investigating such relations are fraught with many complexities and important ethical considerations, there are some cases in which the linkage between genes and physical realization is relatively straightforward. One such case is that of the genetic basis of human color perception.

This paper investigates the linkages between individual's genetic potential for possessing retinal photopigments (or the visual pigments responsible for color perception) and individual color perception differences. We begin by introducing some concepts and terminology that will be used throughout this paper. Next, we review recent key findings in molecular genetics research on retinal photopigment opsin genes. Related results from color perception psychophysics and color and cognition research

\footnotetext{
Portions of this research were presented at the 1998 European Conference on Visual Perception, the 1998 meeting of the Optical Society of America, and the 1998 meeting of the Psychonomic Society. Partial support was provided by the National Science Foundation (Grant NSF9973903 to K.A.J.) and a UCSD Hellman Faculty Award (to K.A.J.). The authors acknowledge the many helpful suggestions made on earlier versions of this manuscript by G. Paramei, L. Hurvich, R. Mausfeld, S. Link, R. M. Boynton, D. I. A. MacLeod, V. Bonnardel, R. G. D’Andrade, N. Alvarado, L. G. Carrera, and K. Goldfarb. Correspondence should be addressed to K. A. Jameson, Department of Psychology, University of California at San Diego, 9500 Gilman Dr., La Jolla, CA 92093 0109 (e-mail: kjameson@ucsd.edu).
}

are then described. Finally, we describe an analysis of color vision genes and present new results from an experiment that investigated the connection between photopigment opsin genes and color perception. We discuss the results of this new research as related to existing color perception theories, as well as the implications for psychologicalstudies of color processing.

To begin, a brief review of the molecular genetics underlying the biological bases of color vision, including defining terms and concepts, is in order. Concepts and terms are simply defined now and are discussed in detail later on. Interested readers can find additional material in Mollon (1995), Nathans (1997), M. Neitz and J. Neitz (1998), and Zegura (1997).

In the present paper, we investigate photopigmentopsin genes, which are simply defined as the genetic sequences responsible for the response properties of the photosensitive material (i.e., opsin tuned cis-retinal) in human retinas. Retinal photopigments occupy cone cells in the retina that respond maximally to specific portions of the visible electromagnetic spectrum. Three general classes of photopigments are known to exist: those most sensitive to the short-wavelength region of the spectrum (abbreviated SWS cones), those most sensitive to the middlewavelength region (MWS cones), and those most sensitive to the long-waveleng th region (LWS cones).

Due to the intricacies of gene expression mechanisms, people who possess the genetic code for the three classes of photosensitive retinal cones may or may not "express" 
all three classes in their retinas. For example, a person with gene sequences for SWS, MWS, and LWS cone types may express, or physically manifest, only two of those types retinally (e.g., SWS and MWS cones). Thus, each person has a genotype (i.e., the genetic potential, or genes, present in their DNA) and a phenotype (i.e., the realized manifestation, or expression, of genetic potentialities in their genetic code). Thus, the phenotype need not be a full representation of the genotype.

The three classes of photopigments respond to visible light and are generally believed to transmit their signals into a postreceptoral neurally trivariant processing system (MacLeod, 1985). This defines the three-channel color signal processing called trichromacy, which governs perceptual behaviors such as color matching. Trichromacy, then, is a theory of color perception based on three receptor classes that feed into three neural channels and that ultimately produce the rich system we experience as color percepts (see Brindley, 1960, pp. 198-221, for further discussion of the three-receptor hypothesis).

A fact that complicates research on this issue is that the only certain method for exactly determining a person's expressed phenotype is to directly examine the retina through "invasive" methods such as microspectrophotometry or in vivo imaging (Roorda \& Williams, 1999). Thus, although tests for color vision abnormalities exist, are widely used (e.g., anomaloscope colormatching and pseudoisochromatic-plate tests), and are fairly accurate in classifying some phenotypes that arise, they are not designed for determining what cell classes are actually expressed in an individual's retinas. In any case, enough can be shown to prove that people exist who are trichromats (i.e., with trivariate color vision), who are dichromats (i.e., lacking one of the three standard signals of color experience, also called color-blindness), and who are anomalous trichromats (with trivariate color vision but with an anomalous shift in the sensitivity in either the LWS or MWS systems).

Shifts in sensitivity found in anomalous trichromats can occur as the result of naturally occurring amino acid mutations (or polymorphisms) in specific locations (or codons) of the gene sequence of a given retinal photopigment class. In such cases, a person may, for example, have normal (or wildtype) SWS and MWS genes but may have a mutated LWS gene (or LWS-photopigment polymorphism) that produces the shift in that cone class's response sensitivity. Polymorphisms of this sort occur rather frequently on MWS and LWS gene sequences and thereby add to the variety of possibly expressed retinal phenotypes in a given population.

It is also possible for a person to possess both a polymorphic variant for a given cone class and the gene sequence for the wildtype, or normal, variant of that same photopigment class. In effect, such people possess the genetic potential for two variants of the same photopigment class, with peak sensitivity at different (albeit very close) spectral frequencies. Such people when female are called heterozygotes, and, below, we assess and review some possible consequences of heterozygote perception.

\section{THE BIOLOGICAL BASIS OF TRICHROMACY}

We start with a review of recent findings relevant to the perception of people possessing more than three classes of retinal cones. The linkage between color perception phenomenology and the neurophysiologicalbasis of color vision has generated an impressive record of psychological and biological research. The 19th century YoungHelmholtz three-component theory developed the idea that color vision is trichromatic due to the presence of three retinal visual pigments, or "photopigments" (see Brindley, 1960). Genetic research showed that color vision is a sex-linked trait, because the genes coding for longwavelength-sensitive (LWS) and medium-wavelengthsensitive (MWS) ${ }^{1}$ photopigments are $\mathrm{X}$ chromosome inherited ${ }^{2}$ and the genetic sequences associated with these photopigments were isolated (Nathans, Piantanida, Eddy, Shows, \& Hogness, 1986; Nathans, Thomas, \& Hogness, 1986). Further work determined that genotypes involving more than three photopigment opsin variants are common and that mechanisms governing the expression of such photopigment opsin genes allow for the possibility of an individual expressing more than three retinal photopigment types (Dartnall, Bowmaker, \& Mollon, 1983; Merbs \& Nathans, 1992a; Mollon, 1992, 1995; J. Neitz \& Jacobs, 1986; J. Neitz, M. Neitz, \& Jacobs, 1993; Winderickx, Battisti, Hibiya, Motulsky, \& Deeb, 1993).

Recent studies show that these commonly occurring genetic polymorphisms produce variations in spectral tuning of expressed photopigments. Such spectral shifts are attributable to amino acid substitutions at specific locations in the opsin gene (Deeb \& Motulsky, 1996). The $\mathrm{X}$-linked inheritance feature, when coupled with the possibility of opsin gene polymorphisms, allows for a considerable percentage of females to be heterozygous at certain critical amino acid positions for MWS or LWS opsin genes. That is, females who possess two distinct genetic variants at certain codons (with one variant on each of two X chromosomes). ${ }^{3}$ Previous research proposed that such genetic heterozygosity may have perceptual consequences in individuals who actually express all four types of photopigment genes, because each gene type produces different retinal photopigment sensitivities, in effect yielding a four-cone-class retinal phenotype (Deeb \& Motulsky, 1996; DeVries, 1948; Jordan \& Mollon, 1993; Krill \& Beutler, 1965; Mollon, 1992; Nagy, MacLeod, Heyneman, \& Eiser, 1981; Schmidt, 1955). ${ }^{4}$

A few investigators have conjectured that some individuals who possess four photopigments in their retinas might have a dimension of perceptual experience that is not experienced by trichromat individuals (Deeb \& Motulsky, 1996; Mollon, 1992, 1995). ${ }^{5}$

As discussed by Cohn, Emmerich, and Carlson (1989) heterozygous females fail to be detected by the use of an anomaloscope, although there are reported shifts in their anomaloscope color matches (Crone, 1959; Feig \& Ropers, 1978; Krill \& Beutler, 1964; Pickford, 1959; Schmidt, 1955), as well as shifts using flicker photometry (Crone, 1959; Ya- 
suma, Tokuda, \& Ichikawa, 1984). However unlike normal controls, these heterozygotes exhibit failures of additivity of trichromatic color matches after exposure to a light bleaching of the rod system (Nagy et al., 1981). Also, heterozygous females for L-cone polymorphisms were found to exhibit higher absolute thresholds to small spots of red light, relative to normal controls (Krill \& Beutler, 1964, 1965). Thus, in some existing research, albeit most of it before 1984, subtle deviations from trichromacy were found using heterozygote participants. ${ }^{6}$ Yet, these subtle deviations were generally considered to be examples of the large individualdifferences possible in color perception and were not interpreted as failures of trichromacy.

More recent psychophysical research has found that expressing four retinal photopigment classes has little impact on the phenomenology of color experience when evaluated using color matching. Specifically, perceptual deviations experienced by four-pigment individuals in psychophysically controlled color-matching tasks have been reported as negligible differences and, as such, are generally seen as continued support for the accepted theory of neural trivariance of the color signal (Jordan \& Mollon, 1993; MacLeod, 1985; Miyahara, Pokorny, Smith, Baron, \& Baron, 1998; Nagy et al., 1981; J. Neitz et al., 1993).

Yet, the existing studies are limited in the ways they assess the color perception of four-photopigment individuals. For example, the studies that report negligible differences in heterozygote color perception generally use the stimulus configuration of Maxwellian-view bipartitefield matching task (e.g., Rayleigh matches using a Nagel anomaloscope). The Rayleigh match stimulus configuration involves monocular viewing of a small spot of $2^{\circ}$ or $10^{\circ}$ (foveal) visual angle presented in a dark surround in which half of the field serves as the stimulus standard composed of a homogeneous yellow light. The observers' task is to adjust the ratio of a mixture of red and green lights to match their sensation in the adjusted-field half of the stimulus to that in the standard-field half of the stimulus (Jordan \& Mollon, 1993; Krill \& Beutler, 1965; Miyahara et al., 1998; Nagy et al., 1981; Schmidt, 1955). ${ }^{7}$ This stimulus configuration is aptly described as a uniform, context-free, noncomplex viewing condition, and it was not designed with the intention to approximate complex real-world viewing situations.

Scenes viewed in the "real world" require a myriad of parameters involving surface reflectances, textures, changing surround context variations, and so on (see Maloney, 1992, for a discussion of parameters required in the "surface complexity condition" of the linear models framework). ${ }^{8}$ Moreover, Mausfeld and Niederée (1993) suggest that even minimal relational stimuli (Maxwellian-view stimuli with chromatic annulus surrounds) require higher than threedimensional models for adequate characterization. There is ample evidence that core mechanisms of color perception are activated only when there is sufficient visual scene articulation. The Rayleigh match situation is simply too im- poverished to activate many classes of mechanisms that are at work in the viewing of real-world stimuli.

In addition, by design, the anomaloscope relies on the fact that people with normal color vision have only two classes of color detectors operating in the red-to-green end of the spectrum (the "blue" cones being essentially silent). However, if an observer received useful information from three different classes of photoreceptors (say, "red," "green," and a third called "red-prime") in the redto-green range of the spectrum, then the Rayleigh colormatching procedure may not provide the degrees of adjustment needed to capture the impact of these three different kinds of color detectors. In view of this, it is perhaps not surprising that findings from some Rayleigh matching circumstances show negligible differences from trichromacy in the color perception of heterozygote females (Miyahara et al., 1998; Nagy et al., 1981). For these reasons, if deviations from trichromacy exist in female heterozygotes, then anomaloscope color matching may not be the best method for capturing such deviations.

Consideration of the psychological literature suggests that gender-based differences in color perception might be a greatly understudied aspect of color and cognition research. Although there is no consensus regarding gender differences in cognitive processing, there are results suggesting that gender plays a role in visual processing domains. For example, findings from the psychological literature show significant gender differences in visual perception, such as persistence of afterimages, Ganzfeld experiences, tolerance of brightness, visual detection thresholds (McGuinness, 1976), contrast sensitivity as a function of spatial frequency and stimulus orientation (Brabyn \& McGuinness, 1979), and color discrimination. McGuinness and Lewis (1976) found females more responsive to the long-wavelengthregion of the frequency spectrum of a stimulus. Gender differences in the visual processing of spatial information are known to exist (Blough \& Slavin, 1987). In response-timed experiments, females generally have greater response time slope values for visual tasks than do males (e.g., Almirall \& Gutierrez, 1987). Some results showing gender differences in response times for visual-spatial tasks may involve subtle features of early retinal signal processing, which combine with cognitive influences (e.g., verbal [females] vs. spatial [male] processing strategies, or different biases toward accuracy) to produce gender differences in visual-spatial behavior. Thus, investigating a gender-linked difference in retinal processing seems warranted, given the potential impact on general psychological processing.

In addition to $\mathrm{X}$-inherited color abnormalities, genderlinked differences in early retinal processing and visual efficiency are also suggested by existing results for two types of red-green color-deficient subjects. As discussed by Nerger (1988), relative to color normal trichromats, the protanopic (i.e., missing the "red" photopigment)photopic luminosity efficiency function (called V-lambda, hereafter denoted $V_{\lambda}$ ) shows an enhanced sensitivity to short wave- 
lengths (Hsia \& Graham, 1957; Wilder, 1970). ${ }^{9}$ Also, $V_{\lambda}$ of protanope individuals peaks at shorter wavelengths, relative to the trichromat $V_{\lambda}$, and exhibits a gross loss of sensitivity in the long-wavelength spectral region (Hecht \& Shlaer, 1936; Hsia \& Graham, 1957; Wilder, 1970). Recent research suggests that updating normative cone fundamentals to reflect dichromat subgroup differences would provide a more appropriate model of the dichromat color response (Sharpe, Stockman, Jaegle, et al., 1998; Stockman $\&$ Sharpe, 1998). Thus, the accepted normative model of responsivity to natural daylight (i.e., $V_{\lambda}$ ) may accurately describe the trichromat response, but it does not, as previously thought, completely generalize as a model of dichromat photopic luminosity response. In view of these findings, it seems reasonable to consider the impact that four-pigment retinal processing might have on accepted standards of $V_{\lambda}$ and normative cone fundamentals.

A related aspect of color perception and cognition behavior is the manner with which individuals categorize and name their color perceptions. Color vision capabilities are believed to be developed and functioning equally in males and females by 1 year of age. In 5- to 6-year-old children, the ability to identify primary colors by name is significantly greater in girls than in boys (although no significant difference is found in the same subjects for drawing geometric designs). The explanation offered is that "various constitutional and environmental factors undoubtedly influence the acquisition of color-naming ability by children," and "verbal skill and interest in colors may vary between boys and girls" (Anyan \& Quillian, 1971,p. 1631). In adults, a number of studies suggest that color lexicons differ in fundamental ways across gender (Lakoff, 1975; Nowaczyk, 1982; Rich, 1977; Swaringen, Layman, \& Wilson, 1978; Thomas, Curtis, \& Bolton, 1978). Comparative cross-cultural studies of some Asian cultures found that females prefer reddish, pink, and purplish colors (Saito, 1994, 1996, 1999).

Furbee et al. (1997) reported gender differences in color naming between males and female subjects. In a study of triadic comparisons of color-sample judged similarity, they found that males and females are differentiated by empirically defined two-dimensional and threedimensional similarity structures. Specifically, females were found to more strongly represent a red-to-yellowto-green dimension relative to their male counterparts (who were negatively correlated with that dimension). This finding suggests that an increased dimensionality in the scaling solution is needed to adequately capture the female representation of color similarity.

These kinds of differences (which are in opposition to a model of shared, pan-gender visual processing mechanisms) went unnoticed or were attributed to possible gender differences in socialization (e.g., Anyan \& Quillian, 1971). Gender differences were not a focus of study for much of the work on the cognition and categorization of color (see Hardin \& Maffi, 1997, for a review), quite simply because, heretofore, gender differences were not suspected as a differentiating factor in color perception.
The interesting question at hand is whether our new understanding of the photopigment opsin genotypephenotype relation warrants a reexamination of the color perception of people with four-photopigment retinas. What aspects of their perceptions may differ from those of trichromats? And, is this X-chromosome-linked genotype the basis of the gender-based differences in color processing that have been observed in the psychological literature thus far? A substantiated gender-specific genotype perceptual relation would represent an important consideration for most psychological studies of color and cognition, including those investigating the dimensionality of color perception space, color memory, color-naming behaviors, and, more generally, color lexicons.

On the basis of the results reviewed above, the present research examines the color perception of individuals exhibiting the genes for four-photopigment retinas. The results are compared with those of individuals exhibiting both the genes and color perception of "normal" threephotopigment retinas and deficient two-photopigment retinas. The aim is to determine whether an experimental task that extends the stimulus complexity beyond the colormatching configuration might reveal $\mathrm{X}$-chromosomebased color perception differences previously undetected in the standard psychophysical tasks. Such an investigation necessarily consists of two distinct components: a laboratory analysis of subjects' photopigmentopsin genes and a behavioral test of subjects' color perception. These two components are now described.

\section{ANALYSES OF PHOTOPIGMENT OPSIN GENES}

The goal of our photopigment opsin genes analyses is to specify the genetic potential of participants in our color perception study. Issues underlying the crucial genetic differences in photopigment opsin genes require a considerable amount of explanation. Appendix A details our rationale and methods and emphasizes that, relative to males and females who have the expected gene sequence (at codon 180) for LWS and MWS genes, the females who have both amino acids (alanine and serine) at codon 180 possess more diverse opsin genes underlying photopigment expression in the retina. As implied above, the interesting question is whether this increased variety of photopigment opsin genes produces differences in color perception in individuals possessing such genes. Investigating this genotype/perceptual-phenotype relation necessitates both a genetic analysis of subjects DNA and an empirical assessment of those subjects' color perception. Genetic analyses reported now are followed by a description of the behavioral experiment conducted. ${ }^{10}$

\section{Method}

Subjects. Sixty-four University of California, San Diego, subjects volunteered through the psychology human subject pool for partial course credit, were solicited by advertisement and partici- 
pated for cash payment, or were volunteers for research participation. DNA specimens from each subject were analyzed in a manner following existing research using standard procedures described in detail in Appendices A and B. On the basis of blind polymerase chain reaction (PCR) genetic assays, 64 subjects were partitioned into the six genotype groups seen in Table 1.

\section{Results}

Table 1 presents the results from PCR genetic analysis of 64 subjects. These results were further refined by results from standard color vision screening methods using the Ishihara Pseudo-Isochromatic Color Plates and the Farnsworth-Munsell 100-Hue Test. ${ }^{11}$ Together, the genetic analysis and the color vision screening results of our subjects allow the determination of the subject partitions given in Figure 1. Figure 1 schematically depicts the genotype-phenotype classifications of our sample of 64 subjects. Figure 1 relates gender partitions to identified genotypes and relates genotype to the predicted phenotype partitions (Figure 1, left column). All predicted phenotype partitions were defined genotypically and, when possible (i.e., for trichromat and dichromat partitions only), were also verified using standardized perceptual tests. Existing color vision screening tests are not ap- propriate, given the heterozygote's potential for deviation beyond trichromacy, for confirming the heterozygote partition. ${ }^{12}$

Genetic analyses (summarized in Table 1) and the subject classification scheme (represented in Figure 1) yield the identification of three subject partitions. These are (1) subjects who are likely expressors of fourphotopigments in their retinas (i.e., 23 female heterozygotes), (2) those likely expressors of three-pigment retinas (i.e., 22 male and 15 female functioning trichromats), and (3) those who may possess the genes required for threepigment retinas but who, due to a genetic expression event, function as if they possess only two retinal photopigments, as indicated by unequivocal failure in standard color vision screening (i.e., 4 functionally dichromat males).

The subjects depicted in Table 1 and Figure 1 also participated in a color perception experiment. The experiment was designed to serve three aims: (1) to go beyond the limitations found in standardized color vision screening, (2) to evade the assumptions of trichromacy inherent in methods that primarily isolate metameric equivalence mechanisms (e.g., Rayleigh matching), and (3) to make use of contextually rich viewing conditions that in-

Table 1

Sixty-Four Subjects Classified by PCR Analyses of Red and Green Gene Codon 180 Amino Acid Sequences

\begin{tabular}{|c|c|c|c|}
\hline $\begin{array}{l}\text { Amino Acids Identified } \\
\text { in Codon } 180 \\
\text { PCR Tests }\end{array}$ & $\begin{array}{l}\text { Possible Configurations of } \\
\text { Phenotypes of Amino-Acids } \\
\text { on } \mathrm{X}_{1}-\mathrm{X}_{2} \text { or } \mathrm{X}_{1}\end{array}$ & $\begin{array}{l}\text { Photopigment Genotypes Suggested by } \\
\text { Amino Acids on Codon } 180 \text { of the } \\
\text { Red and Green Opsin Gene Arrays }\end{array}$ & $\begin{array}{l}\text { Retinal Photopigment } \\
\text { Likely to Arise Given the } \\
\text { Codon } 180 \text { Results }\end{array}$ \\
\hline $\begin{array}{l}\text { Serine and Alanine } \\
\text { Female }(n=23)\end{array}$ & $\begin{array}{l}(\text { Ser }) X_{1}-(\text { Ala }) X_{2} \\
(\text { Ala }) X_{1}-(\text { Ser }) X_{2}\end{array}$ & $\begin{array}{l}X_{\text {Ser: }}: \text { Nrml.R. gene and } \\
X_{\text {Ala }}: \text { Ab.R. gene } \\
\text { or : Nrml.G. gene } \\
\text { or : Ab.R. and Nrml.G. gene }\end{array}$ & $\begin{array}{l}\text { (a) Nrml.R.+ Ab.R. } \\
\text { (b) Nrml.R.+ Nrml.G. } \\
\text { (c) Nrml.R.+ Ab.R.+ Nrml.G. }\end{array}$ \\
\hline $\begin{array}{l}\text { Alanine Female } \\
(n=7)\end{array}$ & $($ Ala $) X_{1}-($ Ala $) X_{2}$ & $\begin{array}{l}X_{\text {Ala }}: \text { Ab.R. gene } \\
\text { or : Nrml.G. gene } \\
\text { or : Ab.R. and Nrml.G. gene }\end{array}$ & $\begin{array}{l}\text { (d) Ab.R. } \\
\text { (e) Nrml.G. } \\
\text { (f) Ab.R.+Nrml.G. }\end{array}$ \\
\hline $\begin{array}{l}\text { Serine Female } \\
(n=8)\end{array}$ & $(\operatorname{Ser}) \mathrm{X}_{1}-($ Ser $) \mathrm{X}_{2}$ & $\mathrm{X}_{\mathrm{Ser}}:$ Nrml.R. gene & (g) Nrml.R. \\
\hline $\begin{array}{l}\text { Alanine Male } \\
(n=14)\end{array}$ & (Ala) $X_{1}$ & $\begin{array}{l}X_{\mathrm{Ala}}: \text { Ab.R. gene } \\
\text { or : Nrml.G. gene }\end{array}$ & (h) Ab.R. \\
\hline $\begin{array}{l}\text { Serine and Alanine } \\
\text { Male }(n=5)\end{array}$ & $($ Ser+Ala $) X_{1}$ & $\begin{array}{l}\text { or: Ab.R. and Nrml.G. gene } \\
\mathrm{X}_{\text {Ser+Ala }} \text { : Nrml.R. gene and Nrml.G.gene } \\
\text { or : Hybrid Nrml.R. + Nrml.G. gene } \\
\text { or : Hybrid Nrml.R. + AB.R. }\end{array}$ & $\begin{array}{l}\text { (j) AB.R.+Nrml.G. } \\
\text { (k) Nrml.R.+ Nrml.G. } \\
\text { (l) Nrml.R. }\end{array}$ \\
\hline
\end{tabular}

Note-Abbreviations as follows: Nrml., normal; AB., abnormal; R., red; G., green. $\mathrm{X}_{1}$ denotes a single $\mathrm{X}$ chromosome, and $\mathrm{X}_{2}$ denotes a second $\mathrm{X}$ chromosome. Column 1 presents subject types grouped by PCR analysis results at codon 180 of the red and green photopigment opsin genes (described in Appendix B). Column 2 suggests the arrangement of amino acids (serine or alanine) on the available X chromosomes for the males and females tested. Column 3 details the photopigment opsin genes most likely arising from the amino-acid sequences identified on the available chromosomes. Column 4 presents possibly occurring photopigment phenotypes given the present genotype analysis. (Phenotypes in column 4 do not include information on the short-wavelength-, or blue-, sensitive pigment gene.) Appendix A provides details of the genotype classification procedure. Note that only one phenotype listed in column 4 involves the expression of two LWS photopigments plus one MWS photopigment [Case (c) of the serine + alanine female group]. Any of the other possible phenotypes listed either have fewer photopigment classes expressed or have the same number of photopigment classes [(f), (j), and (k), which, compared with the probability of expressing (c) or (a) of the heterozygote genotype, are estimated to occur as an expressed phenotype less frequently, given the phenotypes possible within those respective genotypes]. Table 1 presents the most general analysis regarding the codon 180 genotype-phenotype relation. Further complexities arising from gene number, $\mathrm{X}$ inactivation, and other expression mechanisms continue to be studied by molecular geneticists and await specification for the opsin genes. Although the subject group partitions characterized in Table 1 will likely become more complex with further analyses of genetic mechanisms (e.g., the specification of detailed differences implied by MWS gene serine 180, the expression of a greater number of pigment genes from a single X chromosome, or the unresolved expression consequences of chimeric, or hybrid, genes), our crucial assertion that serine + alanine females will exhibit a more diverse opsin genotype and will possess the genetic potential to phenotypically express more kinds of retinal photopigment classes relative to the other subject classes identified here will remain unchanged. 


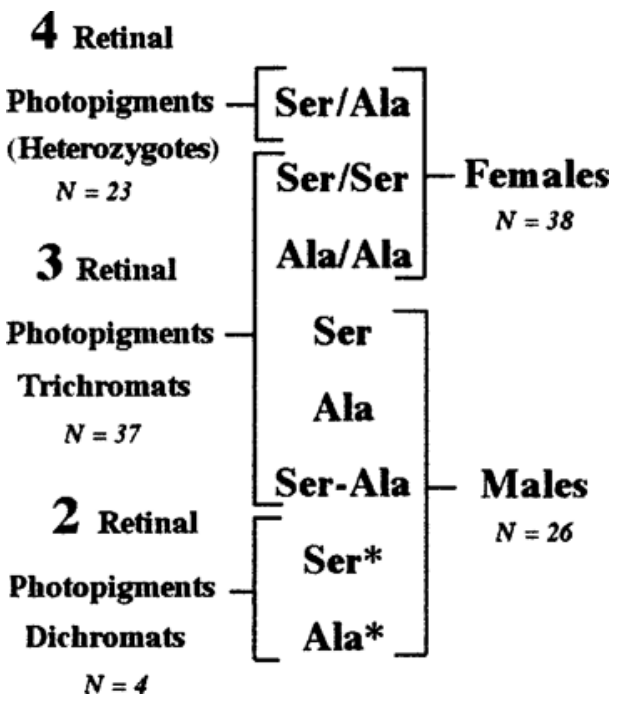

Figure 1. Subject partitions used to analyze the perceptual data. The right column shows the gender distribution of our sample. The middle column shows the distribution of six subject groups (asterisks denote subjects found to be functionally classified as red-abnormal by the Farnsworth-Munsell 100-Hue Test and Ishihara Pseudo-Isochromatic Plates, 11 th ed.). The left column shows the predicted phenotypes based on genotype and color vision assessment. Analysis of the behavioral data uses the classification scheme shown in the left column. Genotypes presented in the middle column were determined by PCR genetic assay described in Appendix B.

voke color discrimination mechanisms. This color perception experiment is now described.

\section{A COLOR PERCEPTION EXPERIMENT USING A DIFFRACTED SPECTRUM STIMULUS}

A spectrum is typically characterized as the component bands of light produced when sunlight is passed through a prism. In 1664, Sir Isaac Newton, followed by Hermann von Helmholtz in 1867, delineated component bands of colored light, or spectral chromatic bands, by drawing lines perpendicularly through spectra. Newton specified seven chromatic delineations in the spectrum (red, orange, yellow, green, blue, indigo, and violet; as referenced in Shapiro, 1984), whereas Helmholtz identified only four color sections (red, green, blue, and purple) in a prismatic spectrum (Campbell, 1986). ${ }^{13}$

To our knowledge, there are no existing theories that provide behavioral predictions for Newton's task of delineating chromatic bands perceived in the spectrum. Nor is there much discussion in the color perception literature of why a person with normal color perception would identify seven bands versus some other greater or lesser number of chromatic bands. When one views a spectral stimulus, one perceives a continuous gradation of color from one end of the spectrum to the other. There is nothing inherent either in the spectrum or in the human perception of it that would compel the identification of the seven chromatic divisions originally identified by Newton or into any other number of divisions found by any subsequent researcher.

The behavioral task used in the present experiment resembles methods used in the early work of Newton and Helmholtz. The stimulus used in the present experiment is a modification of that used in more recent work (Smeulders, Campbell, \& Andrews, 1994) which represents a modern-day consideration of Newton's study of spectral chromatic appearances. Smeulders et al. used a diffracted spectral stimulus in a study of 4 "normal" color vision adults and 1 "protanomalous adult (so-called redblind)" (p. 928). Their task required subjects to identify and delineate bands (i.e., indicate beginning and end points) of colored light in a projected spectrum. In particular, they examined whether progressively more bands were perceived with increasing delineations, and investigated the limits in the number of bands perceived in the subdivided spectrum. Smeulders et al. provided a modern test of the validity of the spectral delineation task introduced by Newton. They did not investigate the linkage between photopigment genotypes and chromatic delineations in a spectrum, which is the focus of the present study.

\section{Method}

Subjects. Sixty-four University of California, San Diego, subjects previously described in the genetic study of photopigment opsin genes participated in the perceptual experiment now described. During the perceptual assessment portion of this study, both subjects and experimenters were naive to the genotyping and phenotyping analysis presented earlier in Table 1 and Figure 1.

Materials. The subjects' task was to provide spectral delineations for a diffracted spectral stimulus subjectively experienced as a selfluminous gradient ordering of chromatic components. Figure 2 presents a schematic of the experimental apparatus used consisting of 10 simple optical components.

Apparatus. Figure 2 schematically depicts the configuration of the experimental apparatus. The light source employed was a 500W halogen illuminant with a broad spectral power distribution extending to the 380 to 780 -nm spectral range, with a component well into the long-wavelength end of the spectrum. All optical equipment was obscured by blackout material, which also eliminated all scattered source light. Measured luminance of the display was 36 lumens $/ \mathrm{m}^{2}$ (very roughly approximating half the brightness of a normal desktop computer display viewed in a well-lit ambient) or 0.4 lumens for the dimensions of our projected stimulus. The diffracted spectrum stimulus was back-projected onto a clear lucite panel mounted in a black $6 \times 5$ foot rigid display. The subject sat in front of the fixed panel and, for each trial, made responses by drawing on the front of the display where translucent tracing paper was mounted. The projected stimulus viewed by the subjects subtended approximately $44^{\circ}$ horizontal $\times 21^{\circ}$ vertical visual angle.

Experimental procedure. The experiment was self-paced, averaging approximately $1.5 \mathrm{~h}$ in duration. Prior to participation, all subjects were fully dark-adapted for a minimum of $15 \mathrm{~min}$. Although the experiment was conducted in dark ambient conditions, the stimulus luminance was well above the rod intrusion threshold for all subjects. The projected diffracted spectrum stimulus was viewed binocularly and was experienced by the subjects as a luminous "rainbow" spanning a horizontal gradient with violet on one extreme end and red on the other extreme end.

A variety of task instructions were used in the experiment to assess different forms of information regarding the subject's percept. 


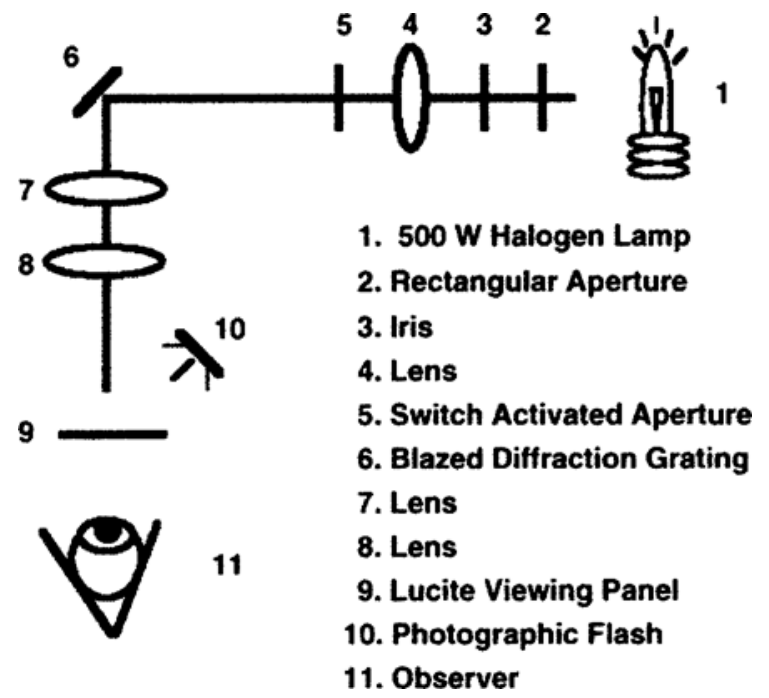

Figure 2. Experiment 1 apparatus and materials. The light source employed was a $500-\mathrm{W}$ halogen lamp (1) with a broad spectrum energy component extending beyond the 400 to $700-\mathrm{nm}$ range and with a substantial component in the long-wavelength end of the spectrum. A rectangular aperture (2) was used as an image plane for collimating the source, and an iris (3) was used to minimize scattered light. Collimated light from lens 4 impinged on a blazed diffraction grating (6) and was controlled by an intervening switch activated aperture (5). Lenses $(7$ and 8 ) were used to form a magnified image of the diffracted spectral image reflected off the grating (6). This image was back-projected onto the Lucite panel (9) and viewed binocularly by subjects. Intertrial energy masking was achieved using a photography flash (10). The entire apparatus depicted in this figure was configured within a $3 \times 3$ foot area (drawing is not to scale).

For example, concerning the width of the subject's percept (or perceived "gamut"), two separate tasks instructed the subject to "Mark the Right [or Left] extreme edge of the rainbow." Regarding the number and location of distinct chromatic bands (a.k.a. "delineations") the subjects responded to eight different task instructions, including "Mark all the edges for all the bands of color in the rainbow," and "Starting from the Left [or Right] side of the display carefully count to the 1 st [or 2 nd, ..., or 7th] band of color and mark both edges of the 1st [or 2nd, ..., or 7th] band of color." Finally, seven different instructions regarding to the location of best-exemplar appearances were used: "Indicate by a single mark the position of the Best Example of Violet [or Blue, Green, Yellow, Orange, Red, or Purple] in the rainbow."

Data from three types of judgments are presented here: (1) the task in which the subjects were instructed to demark "all the edges for all the bands of color in the rainbow" (hereafter called "delineation data"), (2) the task in which the subjects indicated the location of the best-exemplar appearance for several color categories (called "best-exemplar data"), and (3) the task in which the subjects were instructed to "mark the Right [or Left] extreme edge of the rainbow" (called "perceived gamut" data). Each subject's delineation data were based on six repetitions of this task. Each subject's best-exemplar locations were based on three judgments per each color category. Each subject's perceived gamut data were based on three judgments per edge. All judgments were randomly presented within the experiment's 80 total trials.

All subjects were given a different random order of stimuli. Each trial sequence was terminated by actuating a photographic flash, which created an energy mask designed to eliminate stimulus after- images from trial to trial. Between trials, the stimulus was shielded from view by a closed aperture, and the room ambient remained dark while the experimenter (1) set up the response sheet for the next trial, (2) established a calibration mark for the trial, and (3) explained the next task to the subject. Each trial required an estimated $\sim 10-30 \mathrm{sec}$ to complete, with an estimated intertrial interval of $\sim 20-60 \mathrm{sec}$. The physical attributes of the projected display were constant from trial to trial; however, in debriefing, some subjects reported uncertainty regarding whether stimulus manipulations were made across trials. Following the experimental session, subjects were screened for color vision deficiencies using the FarnsworthMunsell 100-Hue Test and Ishihara Pseudo-Isochromatic Color Plates (11th ed.).

We assume that the ability to perceive and delineate bands of chromatic difference along the spectrum is a function of the detection and discrimination of noticeable differences in spectral wavelengths (cf. Boynton, Schafer, \& Neun, 1964; Smeulders et al., 1994). Thus, the relation between photopigment genotype and performance in the spectral delineation task is hypothesized to be that increases in classes of expressed photopigments impact detection and discrimination in such a way as to produce increases in the number of chromatic bands perceived and delineated in the diffracted spectrum.

Regarding a subject's placement of best-exemplar locations in the spectrum, we made the conservative prediction that the data would be comparable to the spectral locations of unitary hues investigated in previous studies (Boynton et al., 1964; Dimmick \& Hubbard, 1939; Purdy, 1931; Westphal, 1910, cited in Boring, 1942). The rationale for this was the following: First, because unitary-hue (or best-exemplar) locations in anomalous trichromats and "normal" trichromats were previously found to be similar for the percepts of blue, green, and yellow, we expected our subjects' data to display a similar agreement. Second, we expected to observe substantial individual variation in best-exemplar locations within all of our subject partitions. Third, we expected that individual variation in some cases would exceed the differences observed between our groups' average locations. Thus, we predicted reasonable correspondences between all our subjects' best-exemplar locations and the spectral locations of unitary hues found in existing research.

Data analysis. As mentioned above, the present analyses examine for each subject (1) the total number of bands delineated in the diffracted spectrum display (six repeated observations per subject), (2) the locations of the best example of the individual colors red, orange, yellow, green, blue, violet, ${ }^{14}$ and purple (three repeated observations per color for each subject), and (3) the locations of each extreme edge perceived in the stimulus (three separate observations per edge, left and right extreme, per subject). All subjects' responses were processed blind and verified for measurement and recording accuracy by two independent experimenters. Unless otherwise stated, all tests of significance reported use two-tailed Student's $t$ tests for unequal samples. All reported tests of significance on mean measures were also verified by appropriate tests on medians.

\section{Results}

Delineation of spectral chromatic bands. Our first hypothesis was that the subjects expressing more than three photopigments would have a different phenomenological color experience. This could be demonstrated in the ways they segment the chromatic components of the diffracted spectrum. Thus, people with four photopigments are expected to experience more chromatic "bands" in the rainbow than are trichromat or dichromat individuals. Similarly, trichromat individuals should experience more bands than should dichromats. With respect to behavioral measures, the general prediction is that the genetic potential to express more than three photopig- 
Table 2

Mean Number of Perceived Spectral Delineations for Four Subject Partitions

\begin{tabular}{lccc}
\hline \multicolumn{1}{c}{ Subject Partitions } & $M$ & $S D$ & $n$ \\
\hline (1) Four-pigment females (of heterozygote genotype) & 10 & 2.96 & 23 \\
(2) Trichromat females & 7.6 & 1.80 & 15 \\
(3) Trichromats (females and males) & 7.3 & 1.93 & 37 \\
(4) Dichromat males (protanopes) & 5.3 & 1.53 & 4 \\
\hline
\end{tabular}

Note-Classification of subject partition (1) is inferred strictly from genotype analyses identifying heterozygote subjects and (on the basis of results found in existing molecular genetics and microspectrophotometry research) is probabilistically linked to the four-photopigment phenotype (with an estimated 50\% incidence of occurrence). Partitions (2), (3), and (4) are based on results from both genotype tests and color vision screening tests. Figure 1 presents the classification scheme for partitions (1), (3), and (4). Partition (2) is a subpartition of group (3) used in comparative analyses.

ments is correlated with an observed increase in the number of chromatic bands perceived and delineated in the diffracted spectrum.

Table 2 summarizes the results for the subject partitions depicted earlier in Figure 1 (four-photopigment females, trichromats, and dichromats). Table 2 also includes data from a subpartition of only trichromat females. Mean number of spectral delineations, standard deviation, and sample size for these four groups are presented. The data in Table 2 confirm that the number of spectral bands that a subject delineates systematically varies with the MWS and LWS photopigments that a subject is presumed to express. As one would predict from trichromatic theory, dichromat individuals (in this case, protanopes) delineate significantly fewer $(p<.05)$ chromatic bands than do trichromats (5.3 vs. 7.3). The number of bands delineated by our four-pigment females (i.e., heterozygotes) and by our male and female trichromat subjects ( 10 vs. 7.3$)$ is also significantly different $(p<.01)$. Interestingly, male trichromats $(n=22)$ and female trichromats $(n=15)$ were not significantly different regarding the number of chromatic bands each group on average delineates $(p=.44)$.

These results show that, in the present task, photopigment genotype predicted the number of chromatic bands a subject perceives, in that increases in perceived chromatic bands were found with increases in retinal photopigment opsin genes. Moreover, the subjects with fourphotopigment retinas perceived significantly greater numbers of chromatic appearances than did the subjects with trichromat retinas. Also, consistent with trichromatic theory, the male and female trichromat subgroups did not differ in the number of chromatic appearances they perceived and delineated.

However, the most stringent test of our hypothesis was between the female trichromatic subjects and the female four-photopigment heterozygote subjects. As shown in rows 1 and 2 of Table 2, the mean numbers of bands delineated by the two groups of females ( 7.6 vs. 10) were significantly different $(p<.01)$. This comparison eliminated differences in performance attributable to gender and thus was a stronger test of our hypothesis that having four pigments yields a perceptual difference. The level of statistical significance observed indicates that these two female groups were not samples of the same underlying population. Overall, Table 2 indicates a systematic relationship between the observed number of bands delineated by the subjects and the number of photopigments they are presumed to express. These results suggest that perceptual color experience for heterozygote females is more articulated than is color perception for "normal" trichromatic subjects.

Note that, as can be seen in the Table 2, the four-pigment females showed much more variability in their judgments (e.g., $S D=2.96$ ) than did the other comparison groups (e.g., $S D=1.80$ for the trichromatic females, and so on). This is consistent with the notion that four-pigment females are judging a more varied color percept, since (1) compared with perceiving only a few chromatic differences, finer grained distinctions (under equal levels of acuity) might produce increased perceptual variation due to the relative perceptual complexity and the need to register a greater number of perceptual distinctions, (2) an empirical task that requires demarkation of greater numbers of perceived delineations would be expected to increase the chances for additional error and variability in judgments, and (3) Poynter (1988) has shown in the general population that more variability is found in judgments for different-color comparisons versus same-color comparisons (i.e., judging brightness of two different colors vs. judging the brightness of two samples of the same color). Thus, if our four-pigment females are actually perceiving a finer gradation of color differences, as these data suggest, then we might expect their judgments to contain more variability relative to those groups who perceive fewer colors in the spectrum.

Finally, the genotype "heterozygote" only probabilistically predicts the expression of a four-pigment phenotype. Thus, our heterozygote partition was likely to include (simply due to genetic expression mechanisms) some females who were genotypically heterozygous but phenotypically trichromat. At present, the only definitive way to determine which heterozygotes unequivocally possess four classes of retinal photopigments is to examine biopsied retinal tissue or to use a new method of imaging the retina that is not yet widely available (Roorda \& Williams, 1999). Phenotype variability in our heterozygote partition would necessarily increase the variability observed in groupwise analyses of data from that subject partition.

Figure 3 presents the locations of chromatic bands delineated by trichromat females $(n=15$; bottom panel) and heterozygote females ( $n=23$; top panel). For each panel, the subjects are rank-ordered on the vertical axis according to each individual's average number of observed delineations. The horizontal axis depicts each subject's series of average delineation positions, with red symbols identifying the beginning of a delineation (or chromatic band), and blue symbols identifying the limit of a delineation. Each horizontal series depicted presents the wavelength location of chromatic bands for each subject, as related to the color gradient presented at the bottom of each panel, given as a rough approximation of the 


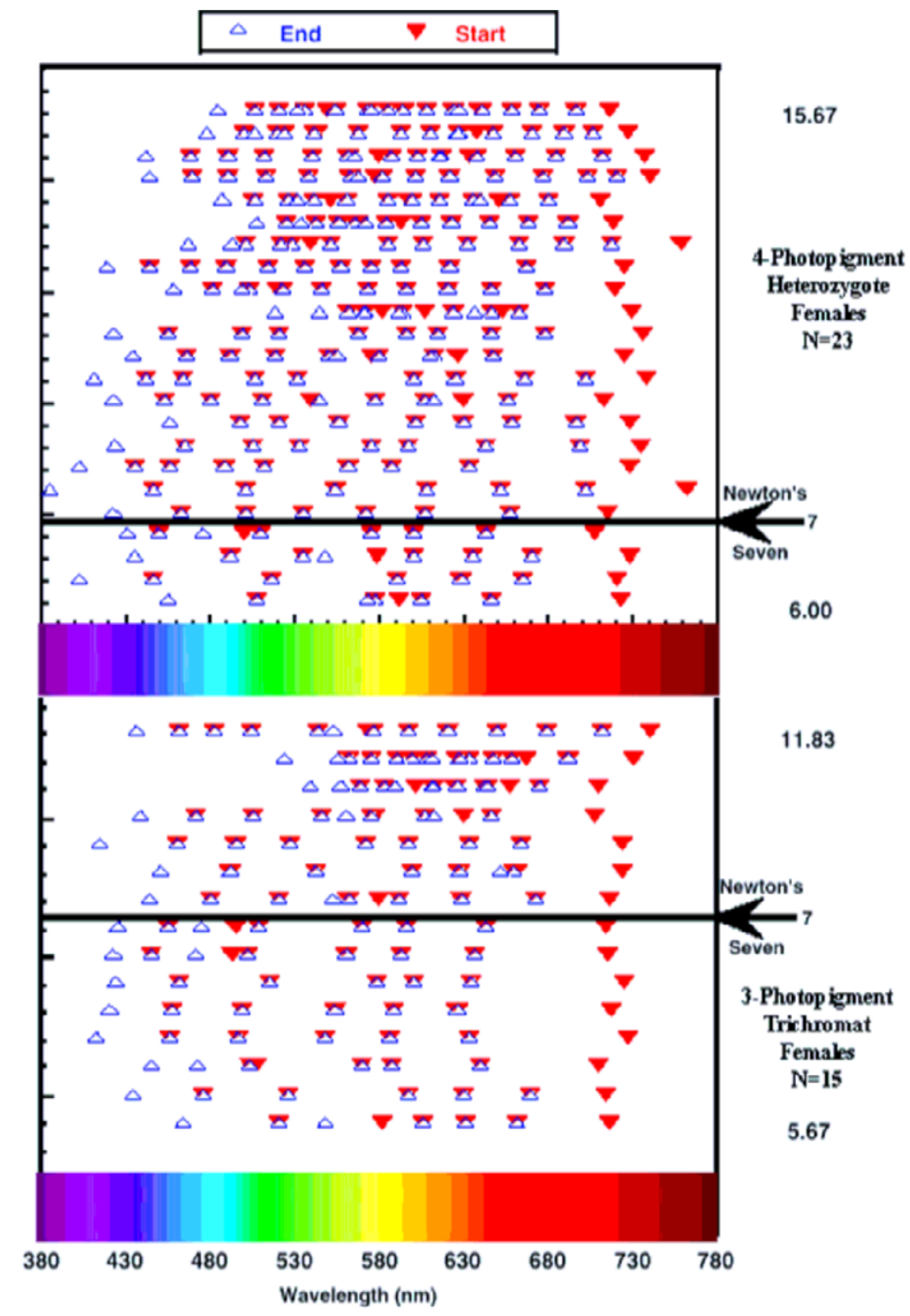

Figure 3. Chromatic delineation locations for trichromat and heterozygote females. The main hypothesis tested is that people with the genetic potential to express more than three photopigments will perceive more chromatic bands in the spectrum than will people who putatively express three or fewer photopigments. The bottom panel represents data from 15 trichromat females and the top panel represents data from 23 four-photopigment females of heterozygote genotype. Red symbols indicate the beginning of a perceived chromatic band, whereas blue symbols indicate the limit of a chromatic band. Thus, the first red symbol located on the far right of either panel denotes the long-wavelength edge of the red band of color, and the blue symbol just to the left of that is the edge that tends toward the middle wavelengths. Successive chromatic bands are similarly defined in both panels. Cases in which red and blue symbols do not coincide reflect within-subjects variance regarding the determination of the position of a particular delineation. The observed repeated-measure error occurs in the two female samples with comparable frequency. The 15 females of the trichromat group (bottom panel) include 7 alanine/alanine genotype individuals and 8 serine/serine genotype individuals. The present analyses do not differentiate the alanine/alanine females from serine/serine females. The top panel presents data from heterozygotes of the serine/ alanine genotype. The vertical axis shows the range of observed banding for each group. Within each group panel, all individual subjects' series of chromatic band locations are presented horizontally. Within-group subjects are rank-ordered vertically with the subjects perceiving the fewest bands represented toward the bottom of a given panel and with the subjects perceiving the greatest number of bands displayed at the top of a panel. 
experimental stimulus. Diffraction (as opposed to refraction) of the spectrum permits the approximation of wavelength by a regression line of measured wavelength against 25 metric distances equally spaced across the stimulus range. Comparing the density and location of symbols across the top and bottom panels illustrates the manner with which the heterozygotes differ from the female trichromats in their chromatic banding behavior: In general, heterozygotes perceived more delineations in the spectrum and exhibited finer grained discrimination differences in the interval between approximately 580 and $780 \mathrm{~nm}$.

Figure 3 also compares the responses of the subjects with Newton's observation of seven perceptible chromatic delineations in the spectrum. Among the heterozygotes, $21(91 \%)$ identified a median number of delineations of seven or more bands, whereas 8 (53\%) trichromat females identified a median number of delineations of seven or more bands. Regarding Newton's hypothesized seven chromatic bands, 4 heterozygotes and 2 trichromat females exhibited a median number of bands equal to seven.

A univariate analysis of variance for between-subjects effects of the width (as the dependent variable) of each subject's spectral range showed that the tested subject groups did not differ significantly regarding the individually perceived width of the diffracted spectrum $[F(3,64)=$ $0.465, p=.79]$. This finding excludes the possibility that increases in banding are simply attributable to an increase in perceived width of the spectrum by individual heterozygotes.

Spectral location of best-exemplar appearances. Our second hypothesis was that the subjects putatively expressing more than three photopigments would not differ significantly from the "normal" trichromat subjects regarding the placement of best-exemplar locations for red, orange, yellow, green, blue, violet, and purple appearances in the diffracted spectrum. Thus, we expected that our heterozygous females would locate the above-mentioned appearances in spectral locations similar to the locations given by the trichromat females and males and that said locations would agree with existing data on the location of unitary hue experiences in the spectrum (Boynton et al., 1964; Dimmick \& Hubbard, 1939; Purdy, 1931; Westphal, 1910, cited in Boring, 1942).

Figure 4 presents the data for the heterozygous females and the trichromat females regarding the placement of best-exemplar appearances for the tested hue categories (red, orange, yellow, green, blue, violet, and purple). ${ }^{15}$ In Figure 4, each horizontal series of symbols represents a single subject's data for the placement of violet, purple, blue, green, yellow, orange, and red bands. Data for the female trichromats $(n=15)$ are displayed in the bottom panel, and data for the female heterozygotes $(n=23)$ are displayed in the top panel. The data from both groups

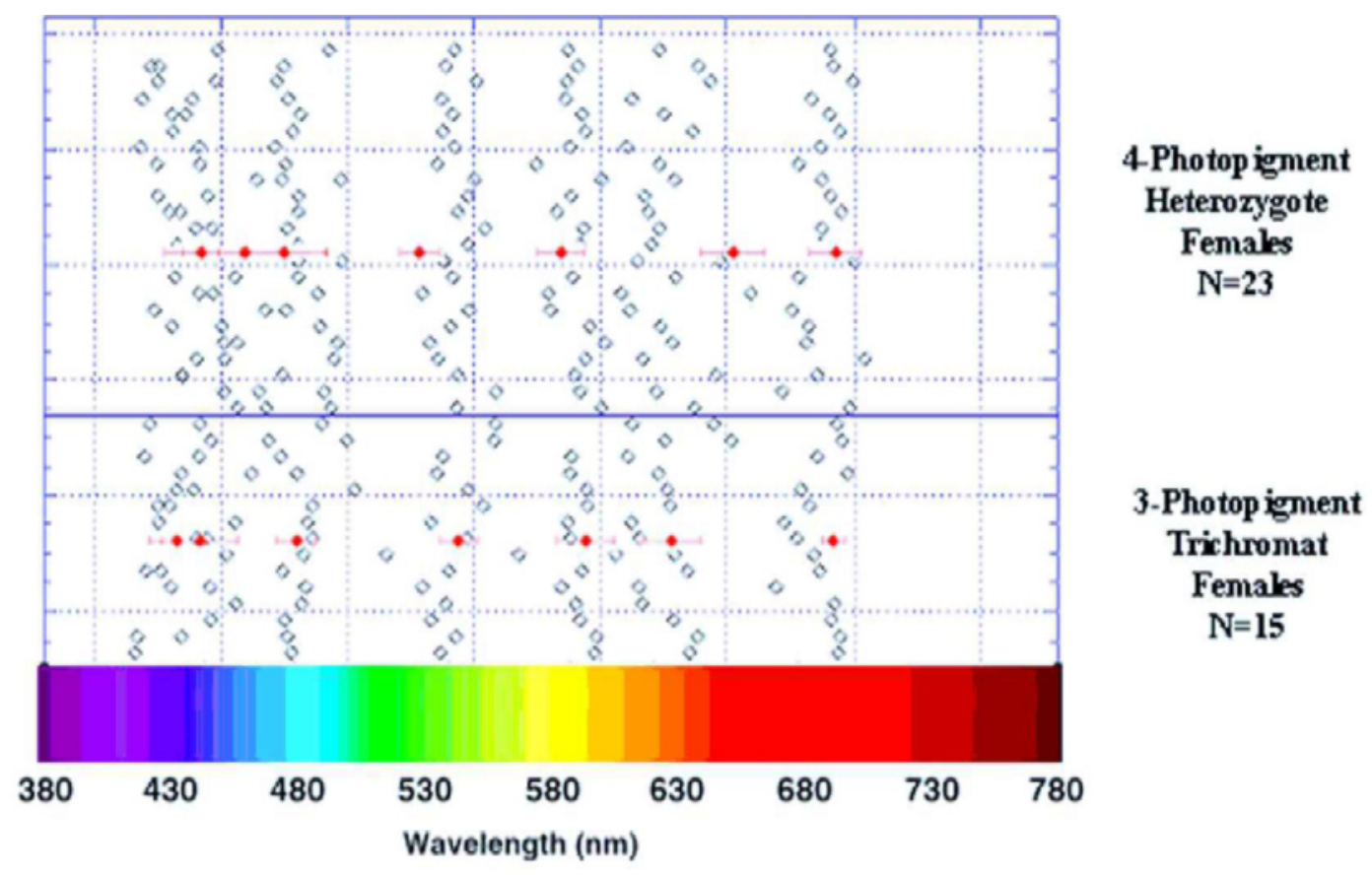

Figure 4. Best-exemplar locations for trichromat and heterozygote females. Similar to Figure 3's representation, individual subjects from each group are represented horizontally as a series of position locations and are separately grouped as trichromats and heterozygotes within the two presented panels. Note that a comparable degree of individual variability in the placement of best exemplars is seen across groups. Individual best-exemplar variability is conveyed by the horizontal spread of points seen in the data columns that define best-exemplar regions for violet, purple, blue, green, yellow, orange, and red (from left to right). Groupwise averages for the placement of best-exemplar locations (represented by the red symbols) are largely in agreement across the two groups (error bars for the groupwise averages represent 1 standard deviation). 
lend support to existing normative data on the spectral location of hue-wavelength association (presumably based on purely trichromatic samples) in that the consensus on the locations of blue, green, and yellow were, respectively, approximations to 481, 539, and $590 \mathrm{~nm} .{ }^{16}$ In Figure 4 , there is also agreement between both partitions of female subjects for the average location of the best exemplars of all the tested appearances. That is, both groups' best-exemplar locations were within one standard deviation of other groups' average best-exemplar locations. ${ }^{17}$

In addition, concerning the location of best-exemplar positions, we found fairly substantial and equivalent amounts of individual variation within each of the subject groups represented. This individual variation was similar for all colors tested, and it occurred to a similar degree across all groups. Further implications of this finding for the general determination of best-exemplar hues and unitary-hue spectral locations will be discussed in a forthcoming paper.

The main result of the best-exemplar location analysis is that, consistent with our prediction, on average the two groups of females we assessed similarly located the positions of hue best exemplars in the diffracted spectrum. This finding indirectly lends confidence to the chromatic banding result presented above and provides another possible clue as to why previous investigations of heterozygote perception did not find color perception differences similar to those we found here in comparisons of female heteorzygotes with female trichromat controls. That is, the heterozygotes' richer color experience may have gone undetected in previous normative research, because (at least for the case of best-exemplar data), aggregating heterozygote data can yield results that resemble that found for trichromat subjects. If the subjects' genotype information were not readily available, one may be unable to differentiate these two groups strictly on the basis of their spectral positions of unitary-hue percepts. An issue of further interest is what such heterozygous color perception differences would contribute to existing normative trichromatic standards (e.g., $V_{\lambda}$ ). We now discuss our results in the context of color perception theories.

\section{DISCUSSION}

The results presented above indicate that, in the present study, female subjects who most likely express four photopigments in their retinas experience a different percept, in comparison with females who most likely express three photopigments. We believe that this kind of increased color-differentiation behavior in heterozygote females has gone undetected because of the empirical methods used in previous research. In contrast to methods previously used to assess the putative four-photopigment vision of heterozygotes, our experiment used binocular viewing of a contextually complex stimulus consisting of a chromatic gradient of heterogeneous luminance. Although the stimulus configuration used here, due to the need for empirical control and manipulation, by no means achieved the viewing complexity present in a "natural" scene, it was clearly a substantial step closer to real-world viewing complexity when compared with a Rayleigh match stimulus configuration. ${ }^{18}$ In the present psychophysical task, the subjects were asked to judge a relatively complex percept. In essence, visual processing in the present study most likely required the use of additional perceptual mechanisms beyond those required by a classical color-matching task. Although added stimulus complexity increases the number of potential explanations for the variation observed, only explanations ultimately based on the serine-180-alanine substitution in photopigment opsin genes (discussed in Appendix A) can explain why, in these data, increased spectral delineations should occur only for heterozygous females.

The photopigment sensitivity curves produced by the serine and alanine opsin variants are believed to be identically gaussian-shaped with peak response sensitivities differing by 4-7 nm (Asenjo, Rim, \& Oprian, 1994; Mollon, 1995; M. Neitz, J. Neitz, \& Jacobs, 1995). Although $4 \mathrm{~nm}$ may seem a minor difference, in many instances, small perturbations in a physical or biological system results in substantial consequences: For example, peak responses of MWS and LWS photopigments differ by an estimated $20-30 \mathrm{~nm}$, but their associated percepts are the distinctly different sensations of green and red (MacLeod \& von der Twer, 2000). Thus, a reasonable assertion is that the serine/alanine 4- to 7-nm difference in photopigment sensitivity could produce a phenomenological effect of two perceptually distinguishable reddish appearances (Mollon, 1992).

Jameson and Hurvich (1956) originally developed the now well-established color-opponency theory, which states that small fixed shifts in photoreceptorspectral sensitivity lead directly to systematic alterations in spectral response functions for the paired chromatic and achromatic opponent response systems. This model has given predictions that agree with data on the color perceptions and discriminations of anomalous trichromats and dichromat observers (Jameson \& Hurvich, 1956). We believe an extension of the theory may similarly serve to describe the perception and discrimination mechanisms governing the color phenomenology of four-pigment observers.

There has been considerable study of the relationship between perceived color and spectral wavelength, and, although there are many variables that effect the appearance of spectral wavelength, the general notion is that "the relation between the wavelength of spectral radiant energy and perceived hue is so well known that it is common-place to talk about [spectral] light as if it were colored" (Boynton et al., 1964). Even so, there are no existing theories in the color perception literature that describe why specific chromatic bands are necessarily perceived by an observer viewing a spectrum. Nor is there an explanation as to why some colors that are associated with wavelength are found to be distinguishable at one location of the spectral continuum but not present at another nearby location. 
The classical three-receptor model of color vision explains that there are three retinal pigments that maximally respond at three different spectral frequencies, and these peak sensitivities are associated with spectral regions subjectively described as reddish, greenish, and bluish in hue. ${ }^{19}$ Additionally incorporated in the established view is a zone theory of color vision (i.e., G. E. Mueller's as discussed in Wyszecki \& Stiles, 1982, pp.634639 ) that provides the mechanistic basis for the location of hues aqua, green, yellow, and orange in the spectrum (presented by Thomson, 1954). Taken together, such a three-receptor-based stage theory (or some variant of it) is generally shared and accepted by color vision scientists as the model underlying color vision processing. However, beyond this, we need further explanatory theory to understand other hue-wavelength relations widely seen in spectra by trichromats (e.g., violet) and heterozygotes (e.g., violet, magenta, burgundy, and salmon). Existing color vision models do not provide an adequate account of the mechanisms underlying perceptual salience for these additional percepts, nor do they formally predict their spectral locations.

We rule out possible color-semantic explanations for these findings and emphasize again that our results are a refutation of the notion that the normative seven chromatic spectral bands (e.g., red, orange, yellow, green, blue, indigo, and violet) are simply culturally acquired, or perhaps are socialized conventions arising from a "basic" color nomenclature. This is seen in that we found that the two groups of subjects who are most likely to be similarly socialized (i.e., females of two different, socially undetectable, genetically based phenotypes) showed significantly different behaviors in our experimental task, whereas two groups of subjects who are most likely to have different socialization experiences (i.e., males and females of trichromat phenotype who receive genderspecific socializations) actually exhibited behaviors that were not significantly different in our task.

The question specifically evaluated by this study is what is at the basis of the observed differences in how individuals perceive hues associated with spectral wavelength, and, in particular, what model will help explain the results found in the present study for the different genotype-phenotype groups we have discussed.

Because the accepted explanations of the red, green, and blue spectral percepts have historically been receptorbased, it makes sense to first extend the receptor-based stage model explanation to account for other perceived spectral bands. To begin with, we could adopt the idea that chromatic appearances are based on the separation or proximity of spectral response-function peaks (DeMarco, Pokorny, \& Smith, 1992; J. Neitz \& M. Neitz, 1994; Piantanida, 1976; Pokorny \& Smith, 1977, 1982; Regan, Reffin, \& Mollon, 1994). This idea states that pigments separated by only $2-3 \mathrm{~nm}$ in effect increase the range of color matching relative to greater pigment separation (Regan et al., 1994). This construct, when combined with the additional input of a fourth photopigment and an added mechanism that accounts for the amount of the total overlap contributed by all available photoreceptor systems at a given wavelength location, would begin to capture the observed increases in discrimination ability as the number of cone classes increases. Such a model could explain why heterozygotes with four overlapping classes of photosensitive cells (some of which are separated by 4-7 $\mathrm{nm}$ ) might experience a finer color discrimination ability in certain regions relative to female trichromats. Such an "area-overlap" mechanism additionally incorporated as a stage in existing zone theories would also account for the pattern of results shown here between all the groups assessed - that is, data from our heterozygotes, "normal" trichromat females and males, and dichromat males. In the present paper, we refrain from elaborating on the details of this photopigment areaoverlap model. Future empirical testing should allow a more detailed description of this idea in a forthcoming report.

One further modeling improvement supposes that the additional photopigment serves two different functions. First, the fourth pigment may possibly be serving as a normal pigment variation that is integrated into a standard three-dimensional structure of metameric classes (thus, heterozygotes with four-photopigment classes expressed are not discernible on the basis of color-matching measures). Second, the fourth pigment may also feed some higher order (probably cortical) mechanisms that take advantage of the signal from the fourth pigment for color discrimination in a way that differs from judging metameric class equivalences. This second possibility is not unlikely since, in other species, wavelength information can be used for various perceptual tasks quite independently from the structure of metameric color codes. That is, color vision and wavelength-dependent behavior can independently coexist in the same animal (e.g., bees exhibit trichromatic color vision exclusively in feeding and in recognition of the hive, while, at the same time, using spectrally narrow-band receptor channels for a variety of other tasks, such as celestial orientation and navigation; see Menzel, 1985, for a discussion). Thus, one might venture the speculation that the present results indicate that the fourth pigment - though it seems to merge with trichromatic equivalence classes of primary codes-is exploited by independent mechanisms that deal with the discrimination of border discontinuity and the like. Such architectural implications very much resemble those from studies on cortical color blindness, or achromatopsia (Stoerig, 1998; Troscianko et al., 1996).

Our results demonstrate that, under experimental conditions using contextually rich viewing circumstances, the heterozygote phenomenological color experience differs significantly from that of the trichromat. What this suggests at the level of theory is that perhaps a reformulation of the model underlying color perception is warranted. Ideally, the reformulation should aim to integrate two apparently different kinds of color perception into a richer more complex model of visual mechanisms. Such a theory might account for the present findings by supposing two different modes of color vision: one em- 
phasizing color equivalence classes, and the other emphasizing color differences. The theory should distinguish between certain psychophysical techniques using noncomplex viewing circumstances as a test of one mode, whereas other more general and realistic viewing circumstances would be more appropriate in assessing the second mode (cf. Poynter, 1988).

We have suggested that one approach toward extending existing models to account for the perceptual impact of four-photopigment retinal processing would involve the refinement of stages in an extended zone theory. Such an extension would also need to take into consideration recent results on the mapping of the retinal mosaic in photoreceptor expression (Roorda \& Williams, 1999) and should also account for the impact of variability in such factors as observer's macular pigmentation (Sharpe, Stockman, Knau, \& Jaegle, 1998), optical density of retinal photopigments (He \& Shevell, 1995), and so on. Such factors would presumably affect the color vision of fourpigment observers in ways similar to that found for threeand two-pigment observers arising from a known genetic linkage (He \& Shevell, 1995).

Concerning the relations between opsin genotype and expressed photopigments, one theory of phenotypic expression (Lyon, 1961) predicts that the retinas of heterozygous females will be a swirled or patchy mosaic of spectrally shifted cells and "normal" cells. Ongoing molecular biology research on the genetic mechanisms underlying various male and female retinal phenotypes will undoubtedly produce more details concerning the diverse range of possible genotypes and the expression of photopigment genotypes for both males and females. At present, four-photopigment female individuals are reported to be rather common, by some estimates occurring in up to $50 \%$ of the female population (M. Neitz, Kraft, \& J. Neitz, 1998). It is also the case that an estimated $8 \%$ of males presumed to be color "normal" likely represent a four-photopigment retinal phenotype (expressing multiple L-pigment opsin gene variants that could significantly contribute to color vision; Sjoberg, M. Neitz, Balding, \& J. Neitz, 1998). All else being equal, our results suggest that if such males were tested in the present study, they would perhaps exhibit an extended percept relative to "normal" trichromats, similar to our findings for heterozygote females.

Thus, heightened color discrimination of the kind demonstrated here reflects a difference in color perception that is correlated with an X-linked inherited trait. This is a factor yet unaccounted for in the psychological study of color processing in a large proportion of female individuals and a smaller, yet sizable, proportion of the general male population. The fact that, in our task, female heterozygotes had a phenomenologically different experience from our group of trichromat females suggests that photopigment opsin genotype differences can give rise to color perception differences in real-world viewing, while producing negligible differences in psychophysical experiments using classical methods of color matching.
These differences may prove to be significant for studies probing models of color vision and color perception spaces. And they suggest that X-chromosome-linked differences in color perception may provide a key development in understanding some of the unexplained gender differences described earlier in color-naming behaviors, color salience and preference, and other color cognitions.

\section{REFERENCES}

Almirall, H., \& Gutierrez, E. (1987). Auditory and visual reaction time in adults during long performance. Perceptual \& Motor Skills, 65, 543-552.

ANYAN, W.R., JR., \& Quillian, W. W., II (1971). The naming of primary colors by children. Child Development, 42, 1629-1632.

Asenjo, A. B., Rim, J., \& Oprian, D. D. (1994). Molecular determinants of human red/green color discrimination. Neuron, 12, 1131-1138.

Blough, P. M., \& Slavin, L. K. (1987). Reaction time assessments of gender differences in visual-spatial performance. Perception \& Psychophysics, 41, 276-281.

BoKER, S. (1997). A measurement of the adaptation of color vision to the spectral environment. Psychological Science, 8, 130-143.

Boring, E. G. (1942). Sensation and perception in the history of experimental psychology. New York: Appleton-Century-Crofts.

Boynton, R. M., Schafer, W. \& Neun, M. E. (1964). Hue-wavelength relation measured by color-naming method for three retinal locations. Science, 146, 666-668.

Brabyn, L. B., \& McGuinness, D. (1979). Gender differences in response to spatial frequency and stimulus orientation. Perception \& Psychophysics, 26, 319-324.

Brindley, G. S. (1960). Physiology of the retina and the visual pathway. London: Edward Arnold.

Buckalew, L. W., \& Buckalew, N. M. (1989). Note on color preference and color vision test performance. Perception \& Motor Skills, 69, 1039-1042.

CAMPBell, F. W. (1986). In search of the spectrum's elusive yellow. Ophthalmic Physiological Optics, 6, 129-133.

Cohn, S. A., Emmerich, D. S., \& Carlson, E. A. (1989). Differences in the responses of heterozygous carriers of color blindness and normal controls to briefly presented stimuli. Vision Research, 29, 255-262.

Crone, R. A (1959). Spectral sensitivity in color-defective subjects and heterozygous carriers. American Journal of Ophthalmology, 48, 231-238.

Dartnall, H. J. A., Bowmaker, J. K., \& Mollon, J. D. (1983). Human visual pigments: Microspectrophotometric results from the eyes of seven persons. Proceedings of the Royal Society of London: Series $B, 220,115-13$.

Deeb, S. S., \& Motulsky, A. G. (1996). Molecular genetics of human color vision. Behavioral Genetics, 26, 195-206.

DeMarco, P., Pokorny, J., \& Smith, V. C. (1992). Full spectrum cone sensitivity functions for X-chromosome-linked anomalous trichromats. Journal of the Optical Society of America A, 9, 1465-1476.

DEVRIES, H. L. (1948). The luminosity curve of the eye as determined by the measurements with the flickerphotometer. Physica, XIV, 367-380.

Dimmick, F. L., \& HubBard, M. R. (1939). The spectral location of psychologically unique yellow, green and blue. American Journal of Psychology, 52, 242-251.

FeIG, K., \& Ropers, H. (1978). On the incidence of unilateral and bilateral colour blindness in heterozygous females. Journal of Human Genetics, 41, 313-323.

Furbee, L. N., Maynard, K., Smith, J., Benfer, B. A., Jr., Quick, S., \& Ross, L. (1997). The emergence of color cognition from color perception. Journal of Linguistic Anthropology, 6, 223-240.

HARDIn, C. L., \& MAFFI, L. (EDS.) (1997). Color categories in thought and language. Cambridge: Cambridge University Press.

He, J. C., \& Shevell, S. K. (1995). Variation in color matching and discrimination among deuteranomalous trichromats: Theoretical implications of small differences in photopigments. Vision Research, 35, 2579-2588. 
Hecht, S., \& Shlaer, S. (1936). The color vision of dichromats. Journal of General Physiology, 20, 57-93.

Hsia, Y. \& GRAham, C. H. (1957). Spectral luminosity curves for protanopic, deuteranopic and normal subjects. Proceedings of the $\mathrm{Na}$ tional Academy of Science, 43, 1011-1019.

JACOBS, G. H. (1998). Photopigments and seeing-Lessons from natural experiments. Investigative Ophthalmology \& Visual Science, 39, 2205-2216.

JAMESON, D., \& Hurvich, L. M. (1956). Theoretical analysis of anomalous trichromatic color vision. Journal of the Optical Society of America, 46, 1075-1089.

Jordan, G., \& Mollon, J. D. (1993). A study of women heterozygous for color deficiencies. Vision Research, 33, 1495-1508.

JuDD, D. B. (1945). Standard response functions for protanopic and deuteranopic vision. Journal of the Optical Society of America, 35, 199-221.

Kraft, T. W., Neitz, J., \& Neitz, M. (1998). Spectra of human cones. Vision Research, 38, 3663-3670.

KriLl, A. E., \& Beutler, E. (1964).The red-light absolute threshold in heterozygote protan carriers. Investigative Ophthalmology, 3, 107-118.

Krill, A. E., \& Beutler, E. (1965). Red light thresholds in heterozygote carriers of protanopia: Genetic implications. Science, 149, 186-188.

LAKoff, R. T. (1975). Language and woman's place. San Francisco: Harper \& Row.

Lyon, M. F. (1961). Gene action in the X chromosome of the mouse (Mus musculus L.). Nature, 190, 372-373.

MacLeOD, D. I. A. (1985). Receptoral constraints on colour appearance. In D. Ottoson \& S. Zeki (Eds.), Central and peripheral mechanisms of colour vision (pp. 103-116). London: Macmillian.

MacLeod, D. I. A., \& VON DER Twer, T. (2000). The pleistochrome: Optimal opponent codes for natural colors. Manuscript submitted for publication.

MALONEY, L. T. (1992). Color constancy and color perception: The linear models framework. In D. E. Meyer \& S. Kornblum (Eds.), Attention and performance XIV: Synergies in experimental psychology, artificial intelligence, and cognitive neuroscience (pp.59-78). Cambridge, MA: MIT Press.

MAUSFELD, R. (1998). Color perception: From Grassman codes to a dual code for object and illumination colors. In W. G. K. Backhaus, R. Kliegl, \& J. S. Werner (Eds.), Color vision: Perspectives from different disciplines (pp. 219-250). New York: Walter de Gruyter.

MAUSFELd, R., \& NiEdERÉE, R. (1993). Inquiries into relational concepts of colour based on an incremental principle of colour coding for minimal relational stimuli. Perception, 22, 427-462.

McGuinness, D. (1976). Away from a unisex psychology: Individual differences in visual sensory and perceptual processes. Perception, $\mathbf{5}$, 279-294.

McGuInNESS, D., \& LeWIS, I. (1976). Sex differences in visual persistence: Experiments on the Ganzfeld and afterimages. Perception, 5, 295-301.

Menzel, R. (1985). Colour pathways and colour vision in the honeybee. In D. Ottoson \& S. Zeki (Eds.), Central and peripheral mechanisms of colour vision (Proceedings of an International Symposium at the Wenner-Gren Center, Vol. 43,pp. 211-233).London: Macmillan.

Merbs, S. L., \& Nathans, J. (1992a). Absorption spectra of human cone pigments. Nature, 356, 433-435.

MerBS, S. L., \& Nathans, J. (1992b). Absorption spectra of hybrid pigments responsible for anomalous color vision. Science, 258, 464-466.

Merbs, S. L., \& Nathans, J. (1993). Role of hydroxyl-bearing amino acids in differentially tuning the absorption spectra of the human red and green cone pigments. Photochemical Photobiology, 58, 706-710.

Miller, S. A., Dykes, D. D., \& Polesky, H. F. (1998). A simple salting out procedure for extracting DNA from human nucleated cells. Nucleic Acids Research, 16, 1215.

Miyahara, E., Pokorny, J., Smith, V. C., Baron, R., \& Baron, E. (1998). Color vision in two observers with highly biased LWS/MWS cone ratios. Vision Research, 38, 601-612.

Mollon, J. D. (1992). Worlds of difference. Nature, 356, 378-379.

Mollon, J. D. (1995). Seeing colour. In T. Lamb \& J. Bourriau (Eds.), Colour, art \& science (pp. 127-150). Cambridge: Cambridge University Press.
Nagy, A. L., MacLeod, D. I. A., Heyneman, N. E. \& Eiser, A. (1981). Four cone pigments in women heterozygous for color deficiency. Journal of the Optical Society of America, 71, 719-722.

Nathans, J. (1997). The genes for color vision. In A. Byrne \& D. R. Hilbert (Eds.), Readings on Color, Vol. 2: The science of color (pp. 249-258). Cambridge, MA: MIT Press.

Nathans, J., Piantanida, T. P., EdDy, R. L., Shows, T. B., \& Hogness, D. S. (1986). Molecular genetics of inherited variation in human color vision. Science, 232, 203-210.

Nathans, J., Thomas, D., \& Hogness, D. S. (1986). Molecular genetics of human color vision: The genes encoding blue, green, and red pigments. Science, 232, 193-202.

Neitz, J., \& JACOBS, G. H. (1986). Polymorphism of the long-wavelength cone in normal human color vision. Nature, 323, 623-625.

NeItz, J., \& NeItz, M. (1994). Colour vision defects. In A. S. Wright $\&$ B. Jay (Eds.), Molecular genetics of inherited eye disorders (pp. 217257). Chur: Harwood.

Neitz, J., Neitz, M., \& Jacobs, G. H. (1993). More than three different cone pigments among people with normal color vision. Vision Research, 33, 117-122.

Neitz, M., Kraft, T. W., \& Neitz, J. (1998). Expression of L-cone pigment gene subtypes in females. Vision Research, 38, 3221-3225.

NeItZ, M., \& NeITz, J. (1998). Molecular genetics and the biological basis of color vision. In W. G. K. Backhaus, R. Kliegl, \& J. S. Werner (Eds.), Color Vision: Perspectives from different disciplines (pp. 101119). New York: Walter de Gruyter.

NeITz, M., NeITZ, J., \& JACOBS, G. H. (1995). Genetic basis of photopigment variations in human dichromats. Vision Research, 35, 20952130.

NERGER, J. L. (1988). The relative numbers oflong-wavelength-sensitive to middle-wavelength-sensitive cones in the human fovea and parafovea. Unpublished doctoral dissertation, University of California at San Diego, La Jolla.

NowACZyK, R. H. (1982). Sex-related differences in the color lexicon. Language \& Speech, 25, 257-265.

Piantanida, T. P. (1976). Polymorphism of human color vision. American Journal of Optometry \& Physiological Optics, 53, 647-657.

PICKFORD, R. W. (1959). Some heterozygous manifestations of colourblindness. British Journal of Physiological Optics, 16, 83-95.

Pokorny, J., \& SMith, V. C. (1977). Evaluation of a single pigment shift model of anomalous trichromacy. Journal of the Optical Society of America, 67, 1196-1209.

Pokorny, J., \& SMith, V. C. (1982). New observations concerning redgreen colour defects. Colour Research \& Application, 7, 159-164.

PoYnTER, D. (1988). Variability in brightness matching of colored lights. Human Factors, 30, 143-151.

PuRdY, D. (1931). Spectral hue as a function of intensity. American Journal of Psychology, 43, 541-559.

Regan, B. C., Reffin, J. P., \& Mollon, J. D. (1994). Luminance noise and the rapid determination of discrimination ellipses in colour deficiency. Vision Research, 34, 1279-1299.

Rich, E. (1977). Sex-related difference in color vocabulary. Language \& Speech, 20, 404-409.

Roorda, A., \& Williams, D. R. (1999). The arrangement of the three cone classes in the living human eye. Nature, 397, 520-522.

SAITo, M. (1994). A cross-cultural study on color preference in three Asian cities: Comparison between Tokyo, Taipei and Tianjin. Japanese Psychological Research, 36, 219-232.

SAITo, M. (1996). A comparative study of color preferences in Japan, China and Indonesia with emphasis on the preference for white. Perceptual \& Motor Skills, 83, 115-128.

SAITo, M. (1999). Blue and seven phenomena among Japanese students. Perceptual \& Motor Skills, 89, 532-536.

SchmidT, I. (1955). A sign of manifest heterozygosity in carriers of color deficiency. American Journal of Optometry, 32, 404-408.

ShapIro, A. E. (1984). The optical papers of Isaac Newton: Vol. 1. The optical lectures 1670-1672 (pp. 539-554). Cambridge: Cambridge University Press.

Sharpe, L. T., Stockman, A., Jaegle, H., Knau, H., Klausen, G., Reitner, A, \& Nathans, J. (1998). Red, green and red-green hybrid 
pigments in the human retina: Correlations between deduced protein sequences and psychophysically measured spectral sensitivities. Journal of Neuroscience, 18, 10053-10069.

Sharpe, L. T., Stockman, A., Knau, H., \& Jaegle, H. (1998). Macular pigment densities derived from central and peripheral spectral sensitivity differences. Vision Research, 38, 3233-3239.

Sjoberg, S. A., Neitz, M., Balding, S. D., \& Neitz, J. (1998). L-cone pigment genes expressed in normal colour vision. Vision Research, 38, 3213-3219.

Smeulders, N., Campbell, F. W., \& Andrews, P. R. (1994). The role of delineation and spatial frequency in the perception of the colors of the spectrum. Vision Research, 34, 927-936.

Stockman, A, \& Sharpe, L. T. (1998). Human cone spectral sensitivities: A progress report. Vision Research, 38, 3193-3206.

Stoerig, P. (1998). Wavelength information processing versus color perception: Evidence from blindsight and color-blind sight. In W. G. K. Backhaus, R. Kliegl, \& J. S. Werner (Eds.), Color vision: Perspectives from different disciplines (pp. 131-147). New York: Walter de Gruyter.

Swaringen, S., Layman, S., \& Wilson, A. (1978). Sex differences in color naming. Perceptual \& Motor Skills, 47, 440-442.

Thomas, L. L., Curtis, A. J., \& Bolton, R. (1978). Sex differences in elicited color lexicon size. Perceptual \& Motor Skills, 47, 77-78.

Thomson, L. C. (1954). Sensations aroused by monochromatic stimuli and their prediction. Optical Acta, 1, 93-102.

Troscianko, T., Davidoff, J., Humphreys, G., Landis, T., Fahle, M., Greenlee, M., Brugger, P., \& Phillips, W. (1996). Human colour discrimination based on a non-parvocellular pathway. Current Biology, 6, 200-210.

WILDER, D. G. (1970). The photopic spectral sensitivity of color normal, protanopic and deuteronopic observers. Unpublished doctoral dissertation, University of California, Los Angeles.

Winderickx, J., Battisti, L., Hibiya, Y., Motulsky, A. G., \& Deeb, S. S. (1993). Haplotype diversity in the human red and green opsin genes: Evidence for frequent sequence exchange in exon 3. Human Molecular Genetics Polymorphism, 2, 1413-1421.

Winderickx, J., Lindsey, D. T., SAnocki, E., Teller, D. Y., MotulSKY, A. G., \& DEEB, S. S. (1992). Polymorphism in red photopigment underlies variation in color matching. Nature, 356, 431-433.

Wyszecki, G., \& Stiles, W. S. (1982). Color science: Concepts and methods, quantitative data and formulae (2nd ed.). New York: Wiley.

Yasuma, T., Tokuda, H., \& IchiKawa, H. (1984). Abnormalities of cone photopigments in genetic carriers of protanomaly. Archives of Ophthalmology, 102, 897-900.

ZEGURA, S. L. (1997). Genes, opsins, neurons, and color categories: Closing the gaps. In C. L. Hardin \& L. Maffi (Eds.), Color categories in thought and language (pp. 283-292). Cambridge: Cambridge University Press.

\section{NOTES}

1. Here, we use the accepted terminology of color vision science: long-wavelength-sensitive (or LWS) and medium-wavelength-sensitive (or MWS) photoreceptors to denote retinal cones maximally sensitive to the long-wavelength portion of the visible spectrum and mediumwavelength portion of spectrum, respectively. By convention, the terms used in genetics research for photopigment opsin genes are red and green for LWS and MWS, respectively.

2. The gene corresponding to the short-wavelength-sensitive, or bluish-sensitive, photoreceptor is located on chromosome 7 and is acquired through autosomal inheritance. Anomalies of this gene are rare and will not be discussed in this paper.

3 . The percentage of females in the general population with heterozygous photopigment opsin genotypes is currently estimated between 15\% (Jordan \& Mollon, 1993) and 50\% (M. Neitz \& J. Neitz, 1998). Among these, $15 \%-20 \%$ of heterozygous females possess dimorphisms in locations of the gene array which are known to impact observers' spectral sensitivities. It is yet unclear whether the cumulative impact of those polymorphisms occuring in less crucial locations of the gene array has a significant impact on the spectral sensitivity of the heterozygous females who possess them.
4. Although phenotypes expressing more than four classes of photopigments are possible, we will limit our discussion to the simplest case involving people expressing four photopigments. The phrase fourphotopigment retinas is used throughout this paper to imply four different classes of photopigments potentially expressed in individuals' retinal cone cells. (The input of the scotopic, or rod, system is not at issue in the discussion presented here.) Genetic mechanisms contributing to phenotypic expression of more than three retinal photopigments is discussed elsewhere (e.g., M. Neitz \& J. Neitz, 1998).

5 . Note that trichromacy is a composite system that, when maximized, consists of the output of three retinal photopigment classes fed into three separate neurophysiological color channels. Individuals with four-photopigment retinas would function as trichromats if, during the process of producing sensations, the visual system reduced the input from the four-photopigment classes into a three-channel system. This four-photopigment/three-channel model has generally been the accepted theory among vision researchers as the most plausible theory for fourphotopigment retinal processing (MacLeod, 1985; Miyahara, Pokorny, Smith, Baron, \& Baron, 1998; Nagy et al., 1981; M. Neitz \& J. Neitz, 1998). The term tetrachromat implies an extension of the three-channel system and is appropriate only for four-photopigment individuals if it were demonstrated that their retinas with four-photopigment classes were feeding into a greater-than-three-channel system and producing a higher dimensional perceptual experience, relative to the trichromat percept. Until such a higher dimensional percept is demonstrated, only the term four-photopigment individuals is warranted for individuals with a four-photopigment class retinal phenotype.

6. Another term for heterozygote females is "female carriers of color abnormality," or "carriers of color-blindness" (Jordan \& Mollon, 1993; Mollon, 1995; Nagy et al., 1981). Typically, female carriers of color abnormality are genetically heterozygous for red-green deficiency. That is, when genetically tested, they usually carry genes for both normal and abnormal photopigments (for one photopigment class) as seen in genetically identified heterozygotes. (Prior to 1985, the manner of identifying carriers of color abnormality was identified indirectly through their color deficient relatives, whereas heterozygotes are identified directly via genetic test.) Female carriers of color abnormality also most likely express three normal pigments in addition to an abnormal shifted retinal pigment.

7. In effect, providing metameric, or phenomenologically matched, equivalences.

8. Interestingly, in Maloney's (1992) formulation, accounting for empirical surface reflectances requires (at least) three degrees of freedom in the surface reflectance functions, which requires four types of photoreceptor parameters in the algorithm. A similar conclusion follows from that discussed by Boker (1997).

9. The amount and range of individual variation are nicely illustrated by Judd (1945, Figure 2).

10. All behavioral data were collected using experimenters and subjects who were naive to the subjects' underlying photopigment opsin genotypes. To simplify the present discussion, however, we present the genetic assay analyses first, followed by the methods and results of the empirical test of subjects' color perception.

11. Note that standard tests available for assessing color vision abnormalities (e.g., Ishihara Pseudo-Isochromatic Plates and MunsellFarnsworth 100-hue test) are specifically designed to detect deviations from normal color vision that arise due to either (1) the lack of a photopigment opsin class of receptors or (2) the shift of one or more of the three photoreceptor classes presumed to exist (or some combination of both 1 and 2). These standard tests were not designed with the assessment of four-photopigment individuals in mind, and, for this reason, they are most likely inconclusive measures of the color perception abilities of four-photopigment retina individuals (an assertion actually supported in the assessment of our subjects). Along these lines, Buckalew and Buckalew (1989), in a sample of 57 women, found an unexpectedly high incidence of female color deficiency (3\% vs. the expected $0.2 \%$ ) using Ishihara plates. It is possible that some of these are expressing four retinal photopigments. Moreover, Cohn et al. (1989) reported that, although heterozygotes are not generally detected by pseudo-isochromatic plates, they observed that when such plates are used under conditions that make the task more difficult (i.e., modification of the spectral profile of the illuminant), the performance of the heterozygote is impaired to a greater 
degree than that of normal controls (p. 256). These findings are consistent with our suggestion, and accord with our data, that such color vision screening tests may erroneously identify four-pigment females as color deficient due to the theory used to construct the screening stimuli.

12. It is essential to note that, although the group of four-pigment heterozygotes in Figure 1 is strictly a genotype classification, no individual in the trichromat or dichromat partition possess the heterozygotes' genetic potential for expressing four photopigments. The overwhelming implication from existing genetics data on nonhuman primates and human retinas (e.g., Kraft, J. Neitz, \& M. Neitz, 1998) is that a genotypic female heterozygote will very likely be an expressor of a fourphotopigment retina. However, this cannot be verified in our subjects because physical access to their retinas was not possible; nor is it verifiable through any standard color vision screening test. By comparison, the trichromats and dichromats groups in Figure 1 have both (1) been shown by genetic analysis to have three photopigment genotypes (including anomalous genotypes that are known to produce, with a high probability, functionally color-blind males) and (2) been shown by standard color vision screening tests to be functionally trichromats and dichromats, respectively. Thus, the analysis in Figure 1 makes use of all available and appropriate measures for phenotype determination and necessarily imposes the mixed genotype-phenotype nomenclature four-photoigment heterozygotes, trichromats, and dichromats for our three subject groups.

13. A prismatic spectrum refers to the component rays of light produced by refraction when a broadband source, such as sunlight, is passed through a prism. A more precise way of creating a spectrum of component rays of light is by using diffraction rather than refraction. The two methods give rise to essentially the same end-product stimulus (i.e., a spectral stimulus appearing as a self-luminous rainbow-like gradient with colors ordered red, orange, yellow, green, blue, etc.), with the exception that, relative to prismatic refraction, the diffracted spectrum has the advantages of being linearly related to wavelength by a relationship precisely specified by the diffraction grating parameters.
14. Violet was tested rather than Newton's indigo because it was presumed that the latter color category might not be as widely known among college undergraduates.

15. Figure 4 uses the same metric scale distances computed and represented in Figure 3 described earlier.

16. Spectral locations of the additional chromatic appearances tested here (i.e., orange, violet, and purple) have not been widely studied in color vision research (see Dimmick \& Hubbard, 1939, p. 245).

17. Although the data from our male subject groups are not represented in Figure 4, it is worth mentioning that the trichromat males in general located best exemplars in similar positions as to those located by the two female groups presented and also supported existing data on the spectral locations of unitary blue, green, and yellow. Our dichromat subjects' best-exemplar location data differed from those of the other tested subjects in ways one would expect given the color vision deficiencies experienced by the subjects in the dichromat group.

18. That is, the stimulus used here is sufficiently rich to activate internal mechanisms that are relatively closer to the mechanisms involved in viewing real-world scenes. By comparison, these mechanisms are silent in the Rayleigh bipartite field viewing condition. An aspect that distinguishes our stimuli from the Rayleigh match situation is that our visual scene fulfills an important requirement for the activation of mechanisms that underlie the perception of real-world scenes- that is, a sufficiently high variation with respect to chromatic and luminance codes (as discussed by Mausfeld, 1998, pp. 223-224). There is ample evidence that core mechanisms of color perception are activated only if there is sufficient articulation that requires (at least) three degrees of freedom in surface reflectance functions implemented by Maloney (1992) using an algorithm, which, interestingly, requires four types of receptor parameters in the "surface complexity condition."

19. Allowing for the fact that each triple of distinct hue-wavelength sensations experienced by a given trichromat individual will vary somewhat from that of any other trichromat individual.

\section{APPENDIX A}

Appendix A first describes the rationale for the genetic analysis component of this study and then describes the genotype variants and possible phenotypes arising when amino acid substitutions occur on codon 180 of the MWS (green) and LWS (red) gene sequences.

\section{Genetic Structure Underlying Visual Pigment Variation}

Because the molecular structures of the LWS and MWS visual pigment gene bases are $98 \%$ identical to each other, there are relatively few locations in the amino acid sequences where the LWS and MWS genes can be differentiatedby a genetic test (Asenjo et al., 1994; Nathans, Piantanida, et al., 1986; Nathans, Thomas, \& Hogness, 1986). For the LWS and MWS pigment genes, these include only 18 variable amino acid positions (see Jacobs, 1998, p. 2208). Substitutions of amino acids caused by differences in the genetic sequence can eventually produce different spectral absorption properties in retinal cones. These "dimorphic" or "polymorphic" sites are locations in the gene sequence where two different amino acids can be alternatively present. Among these 18 sites of variation, only 7 (at codons 116, $180,230,233,277,285$, and 309) involve amino acid substitutions that produce shifts in spectral absorption of the X-linked photopigment opsins (Deeb \& Motulsky, 1996; Jacobs, 1998).A1

One position in particular, position 180 on exon 3 of the LWS and MWS genes, is one of three positions in the gene sequence (along with codons 277 and 285 at which LWS and MWS genes can be uniquely distinguished) where a single amino acid substitution determines a major portion of the spectral shift between
LWS and MWS color vision pigments (Asenjo et al., 1994). This is exemplified by the fact that amino acid substitutions at codons 180,277 , and 285 can eventually transform a red-sensitiveretinal photoreceptorinto a green-sensitivephotoreceptor,and vice versa.

In the present study, we specifically examined this important codon (serine-180-alanine) of the gene sequence because this position has the following properties: (1) it is one of the seven sites where an amino acid substitution or "polymorphism" occurs, ${ }^{\mathrm{A} 2}(2)$ it is believed to produce some of the most substantial shifts in spectral sensitivity (Asenjo et al., 1994; Merbs \& Nathans, 1993); (3) in general, shifts are readily apparent in codon 180 of the L-pigments but are either smaller or not detected in the M-pigments as evidenced by the measured spectral peaks (Asenjo et al., 1994; Merbs \& Nathans, 1992b, 1993); and (4) substitutionsoccurring at position 180 are likely to yield the largest L-pigment peak absorption shift (M. Neitz \& J. Neitz, 1998). Compared with relatively smaller spectral shifts produced by changes that occur at other locations in the gene array, the amino acid substitutions at position 180 play an essential role in producing individual differences in normal color vision and also play a role in modulating the severity of color vision defects (M. Neitz \& J. Neitz, 1998). Thus, codon 180 is a crucial site to consider when investigating the impact of shifted-peak spectral sensitivity on perception.

We examine the presence or absence of amino acid substitutions observed at codon 180 for both red and green opsin genes simultaneously. What can one infer regarding possible retinal phenotypes from genetics tests on specific codon 180 amino 


\section{APPENDIX A (Continued)}

acids in either the red (LWS pigment) or the green (MWS pigment) opsin gene? Although larger sample sizes are needed to accurately assess the population frequency of the serine-180 shift versus the alanine-180 shift, some investigations suggest that the general Caucasian population shows a $\sim 56 \%$ occurrence for the "normal" serine 180 and a $44 \%$ occurrence of a polymorphic mutation alanine 180 for the red pigment gene. By comparison, the frequency of occurrence for the green pigment gene is $\sim 96 \%$ "normal" alanine 180 and $\sim 4 \%$ polymorphic serine 180 (Winderickx et al., 1993).

Asenjo et al. (1994), M. Neitz and J. Neitz (1998), and Sharpe, Stockman, Jaegle, et al. (1998), show that the serine amino acid at codon 180 is primarily linked to the normal red gene, whereas the presence of alanine at codon 180 can indicate the presence of a polymorphic (shifted) red photopigment gene, the presence of a normal green gene, or the presence of both a shifted red and a normal green gene. Winderickx et al. (1992) suggest that MWSpigment gene 180 substitutions of serine for the normal alanine occurs with far less frequency than in the LWS-pigment gene. When MWS 180 substitutions do occur, they produce nonsignificant shifts in the absorption spectra of M-cone retinal photopigments (Asenjo et al., 1994). ${ }^{\text {3 } 3}$

At present, the consensus is that, although the resulting spectral sensitivity shifts produced by codon 180 substitutions are significant for LWS-pigments, they are far less common for MWS-pigments, and, when present, they yield MWS-pigment spectral absorption peaks essentially identical to the "normal" MWS-pigment (M. Neitz \& J. Neitz, 1998). For the above reasons, we analyzed subjects' DNA to specify the amino acids present at codon 180 in the red and green genes. We now summarize the resulting genotype variants arising from the presence or absence of particular codon 180 amino acids and the majority of possibly occurring phenotypes.

\section{Classifying Photopigment Opsin Genotypes}

On the basis of existing findings (Asenjo et al. 1994; M. Neitz \& J. Neitz, 1998; Sharpe, Stockman, Jaegle, et al., 1998; Winderickx et al., 1993; Winderickx et al. 1992), presence of codon 180 amino acid variants for either the red or the green gene allows several possible phenotypes to be expressed. These are summarized as follows:

(1) The presence of serine at codon 180 implies the detection of a normal red gene (because serine is primarily linked to the normal red gene at position 180); $\mathrm{A} 4$ and (2) the presence of alanine at codon 180 can indicate the presence of a polymorphic L-pigment gene (with a substantially shifted peak spectral sensitivity from the normal L-pigment gene), the presence of a normal M-pigment gene, or the presence of both a shifted red gene and a normal green gene.

What these scenarios imply for possible phenotype expression is relatively straightforward when dealing with males who have only a single maternally inherited X chromosome. In this case, we know when we observe a male who tests positive for the presence of both serine and alanine and who possesses a single $\mathrm{X}$ chromosome with at least one normal red gene and with at least one normal green gene or a mutated red gene (we say "at least one" because we cannot rule out red and green gene copies occurring at other sites in the red and green gene sequences since we do not consider other sites in this analysis).

By comparison, when we observe a male who tests positively for serine 180, we can infer that this individual has a normal red gene at codon 180 , but not a normal green gene or a polymorphic red gene at position 180 .
Likewise, we would infer that a male with alanine 180 would have either a normal green gene or a polymorphic red gene at codon 180 , but not a normal red gene at 180 .

The same codon 180 analysis for females is complicated by the fact that, relative to males, females have two $\mathrm{X}$ chromosomes capable of carrying red and green genes at codon 180. In females, one $\mathrm{X}$ chromosome is transmitted via maternal inheritance, whereas a second $\mathrm{X}$ chromosome is paternally inherited.

If we consider a female who tests positive only for the presence of serine at position 180 , the following possibilities are allowed: this female has two X chromosomes, each with one normal red gene. One copy occurs on codon 180 of the first $\mathrm{X}$ chromosome $\left(\mathrm{X}_{1}\right)$, while a second identical copy might be found on codon 180 of the second chromosome $\left(\mathrm{X}_{2}\right)$. The less probable scenario is that only one of the $\mathrm{X}$ chromosomes has opsin genes at position 180, and the second chromosome has none of the described red opsin genes at 180. Regardless of the scenario, this female still has at least one copy of the normal red gene.

Alternatively, consider a female who tests positive for the presence of the alanine polymorphism at position 180: This female has two $\mathrm{X}$ chromosomes, each with a normal green gene or a polymorphic red gene at codon 180 , but not a normal red gene at 180 (although we cannot rule out a normal gene occurring elsewhere on another amino acid position in the red gene array). Thus, for this female, we observe the presence of a normal green gene and a mutated red gene on $X_{1}$ and copies (or a subset of copies) of that normal green gene and a mutated red gene on $\mathrm{X}_{2}$. Depending on the order of these different genes in the red and green sequences of $X_{1}$ and $X_{2}$, and depending on $X$ inactivation and other expression mechanisms, this female has the potential for codon 180 to produce at most a normal green photopigment opsin and a shifted red photopigment opsin.

Even more varied is the female who tests positive for the presence of both serine and alanine amino acids at codon 180 . In this heterozygote female, we observe an individual with two $\mathrm{X}$ chromosomes, each with at least one normal red gene and with at least one normal green gene or a mutated red gene. It is possible that, for this female, the first $\mathrm{X}$ chromosome $\left(\mathrm{X}_{1}\right)$ could have a different subset of genes from the second chromosome $\left(\mathrm{X}_{2}\right)$. Thus, the this female might possess a normal red gene, a normal green gene, and a mutated red gene on $\mathrm{X}_{1}$ (or some subset of these genes); and on $\mathrm{X}_{2}$ also a normal green gene and a mutated red gene. Depending on the order of these different genes in the red and green sequences of $X_{1}$ and $X_{2}$ and depending on $\mathrm{X}$ inactivation and other expression mechanisms, this serine-180-alanine female has more codon 180 gene combinations possible on her two chromosomes than any of those males or females described above.

\section{Appendix A Notes}

A1. The other 11 positions are sites where the amino acid sequence can vary but where such variation does not produce shifts in spectral absorption at the level of the retinal cones.

A2. In a study of 45 color abnormal males, Sharpe, Stockman, Jaegle, et al. (1998) report "except for position 180 the highly polymorphic nature of the amino acids within exon 3 makes it impossible to discern whether any particular exon 3 is derived from a red or a green pigment gene" (p. 10059). While the Sharpe, Stockman, Jaegle, et al. study does not focus on "normal" color vision, male and female, subjects, it does provide results which lend insight and may be generalized in the present study until a more extensive study of color normals is completed.

A3. Moreover, according to Sharpe, Stockman, Jaegle, et al. (1998), "among red-green hybrid genes that carry serine at position 180, exon 
3 (within which codon 180 resides) is more likely to derive from a red pigment gene, whereas among red-green hybrid genes that carry an alanine at position 180, exon 3 may have originated from either a green or a red pigment gene" (p. 10060). Thus, at least for the sample of 45 males studied by Sharpe and colleagues, the presence of serine at position 180 is more likely to imply a red gene than a green gene polymorphism, and the presence of alanine at 180 implies either a green gene or a red polymorphic variant.

A4. In a study of 45 dichromats, Sharpe, Stockman, Jaegle, et al. (1998) found that when serine 180 occurs, it is either within exon 3 of a red gene in deuteranopes (8-28 in their Table 2) or within the exon 3 red portion of a hybrid red-green gene of a protanope (30-35 in their Table 2). J. Neitz et al. (1993) also found in 16 color normal males no occurrence of green gene encoding Serine-180. And Sjoberg et al. (1998) in 130 normals found M-serine- 180 with 0.070 frequency. Thus, until further study clarifies the linkages, we assume here that serine 180 is generally linked with the red gene even when occurring in hybrid red-green genes that get expressed as green. This is why the serine 180 substitution is not found to influence the M-pigment spectral sensitivity.

\section{APPENDIX B}

Appendix B describes the procedures used for the detection of codon 180 polymorphisms by way of the polymerase chain reaction (PCR) method. PCR analyses were verified with DNA sequencing.

\section{DNA Extraction}

Three milliliters of venous blood were collected from each subject into EDTA (purple top) tubes using standard antiseptic blood-drawing techniques, following receipt of approval from the UCSD Institutional Review Board (IRB 970908). Using standard methods (Miller, Dykes, \& Polesky, 1998), DNA was extracted from peripheralblood leukocytes using the PureGene DNA Extraction Kit (Gentra Systems, Minneapolis, MN). DNA concentration was determined by evaluating the DNA absorbance at OD 260 using a spectrophotometer(Ultrospec III, Pharmacia).

\section{PCR Schema for Amplification of DNA Sequences Specific to the Red Opsin Gene}

DNA sequences for the green and red opsin genes were downloaded from GenBank (http://www.ncbi.nlm.nih.gov; GenBank Accession Nos. Z68193, M13306, K03490, K03491, K03492, $\mathrm{K} 03493$, and K03494). The S180A polymorphism in the red opsin gene occurs in exon 3 . The S180A polymorphismcreates a $t$ to $g$ substitution in the red opsin DNA sequence, making the red opsin exon 3 DNA sequence identical to the green opsin DNA sequence (Nathans et al., 1986).

The Oligos 4.0 software program was used to identify primer sequences that would encompass the S180A polymorphism within exon 3. Because the red and green opsin gene DNA sequences are identical through this region, both red and green exon 3 sequences will be generated using this primer set. The $5^{\prime}$ or sense primer is located in intron 2 at nt 14089-14109, 150 nt from the beginning of exon 3 (GenBank Accession No. Z68193). The $3^{\prime}$ or antisense primer is located at nt 14387-14407 and corresponds to the last 21 bases of exon 3 . This primer pair would be expected to generate a 318 bp PCR amplicon.

\section{Detection of the Codon 180 Polymorphism}

The $\mathrm{T}$ to $\mathrm{G}$ polymorphism at amino acid codon 180 in the red opsin gene changes the DNA coding sequence from "atc tgg $t \mathrm{ct}$ gct" to "atc tgg gct gct" (corresponding to amino acid sequence "ile trp ser ala," which is changed by the $t$ to $g$ polymorphism to "ile trp ala ala"). The $t$ to $g$ change in the red gene makes the red exon 3 amino acid sequence identical to the amino acid sequence of the green exon 3 amino acid sequence. The $t$ to $g$ change creates a DNA sequence recognized by the restriction endonuclease Fnu4HI. As a result, the presence of the ala at amino acid position 180 can be detected by digesting the PCR amplicon with the Fnu4HI enzyme.

\section{PCR Amplification Conditions}

Three hundred nanograms of DNA were amplified in $50 \mu \mathrm{l}$ of $50 \mathrm{mM} \mathrm{KCl}, 10 \mathrm{mM}$ Tris- $\mathrm{HCl}, \mathrm{pH} 8.3,0.01 \%$ gelatin, $2.5 \mathrm{mM}$ $\mathrm{MgCl}$, $200 \mu \mathrm{M}$ dNTP's, $500 \mathrm{nM}$ primers, and $1 \mathrm{U}$ Taq DNA polymerase (Perkin Elmer). Thermocycling parameters were as follows: denaturation of the DNA at $94 \mathrm{C}$ for $3 \mathrm{~min}$, followed by 30 cycles of $94 \mathrm{C}$ for $1 \mathrm{~min}, 55 \mathrm{C}$ for $1 \mathrm{~min}, 72 \mathrm{C}$ for $1 \mathrm{~min}$, with a final 5-min extension at $72 \mathrm{C}$ (Ericomp, San Diego, CA).

Twenty microliters of PCR product were digested in $2 \mathrm{U}$ Fnu4HI (New England Biolabs) and $2 \mathrm{mM}$ Tris-acetate, $1 \mathrm{mM}$ magnesium acetate, $5 \mathrm{mM}$ potassium acetate, and $0.1 \mathrm{mM}$ di-

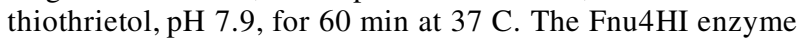
was inactivated by a 5-min incubation at 65 C. Digested and undigested PCR products were size-fractionated side by side on a $2 \%$ agarose gel in $1 \mathrm{X}$ TAE buffer, using the HaeIII DNA molecular marker as a size standard (Promega), visualized by ethidium bromide staining with a UV transilluminator (UVP, Inc.) and photographed.

(Manuscript received March 16, 2000; revision accepted for publication October 17, 2000.) 